\title{
Two faces of the attentional blink: Gradual and discrete loss of perceptual awareness
}

Aytaç Karabay $^{1}$, Jing Wang ${ }^{234}$, Sophia A. Wilhelm ${ }^{1}$, Sander Martens ${ }^{34}$, \& Elkan G. Akyürek ${ }^{1}$

${ }^{1}$ Department of Psychology, Experimental Psychology, University of Groningen, The

Netherlands

${ }^{2}$ Brain Function and Psychological Science Research Center, Shenzhen University, China

${ }^{3}$ Cognitive Neuroscience Center, University of Groningen, The Netherlands

${ }^{4}$ Department of Biomedical Sciences of Cells \& Systems, University Medical Center Groningen,

The Netherlands

Running head: Two faces of the attentional blink

9/13/2019

Word count: 12551

Address correspondence to:

Elkan Akyürek

Department of Psychology, Experimental Psychology, University of Groningen

Grote Kruisstraat 2/1, 9712 TS Groningen, The Netherlands

Email: e.g.akyurek@rug.nl

Telephone: $+31(0) 503636406$ 


\begin{abstract}
In a series of experiments, the nature of perceptual awareness during the attentional blink was investigated. Previous work has considered the attentional blink as a discrete, all-or-none phenomenon, indicative for access to conscious awareness. Using continuous report measures in combination with mixture modeling, the current outcomes show that, in fact, the attentional blink can be a gradual phenomenon. The nature of the blink depended on whether targets might compete for the same spatial location or not. Without the possibility of spatial overlap, the attentional blink was of a gradual nature, in which representations of blinked targets were impoverished, but nonetheless approached the actual identity of the target that was presented. Conversely, with spatial overlap, the attentional blink was discrete; no partially correct reports could be made about blinked targets. These two different faces of the attentional blink challenge current accounts of awareness and temporal attention, which do not recognize the critical role of feature-location binding in producing discrete task performance, and consequently cannot explain the existence of gradual awareness, including that of targets subject to the attentional blink.
\end{abstract}

Keywords: attentional blink, perceptual awareness, working memory, continuous report, precision, guess rate 
Attention is a critical cognitive function. Through the attentional selection of objects and events of interest, at the expense of other items that appear less interesting, cognition can be devoted to information that is likely to be relevant. Attention strongly drives human behavior: We act on what we select and process cognitively, not on things that are ignored. Although certain basic properties of an object or event might be registered by the brain independent of attention (e.g., a global motion path), attention generally limits entry to higher-level processing, as is needed to actually identify and name an object. The importance of selective attention is also evident from its close relationship with conscious awareness, which is similarly concerned with only one or a few items at any one time (e.g., Posner, 1994).

The selective nature of attention is both its strength and its weakness. Its selectivity assures that not everything that is sensed is subsequently processed in-depth, allowing major savings in cognitive expenditure. However, attentional selectivity also implies a limited ability that can fall short when there are more than a few items of interest present. It is therefore not surprising that failures of attention are thought to contribute to human error (Endsley, 1995). A compelling demonstration of the very limited nature of attention is the attentional blink (AB) phenomenon. The $\mathrm{AB}$ is the difficulty in selecting a task-relevant target stimulus if it occurs within approximately half a second after another target (Broadbent \& Broadbent, 1987; Raymond, Shapiro, \& Arnell, 1992). Without selecting that prior target, or with sufficient time in-between, no difficulty is experienced. Thus, regardless of the specific theoretical interpretation (for an overview, see Dux \& Marois, 2009; Martens \& Wyble, 2010), it is evident that the attentional processing of just a single preceding target already strongly impairs the processing of the following one, and does so for a considerable length of time.

The $\mathrm{AB}$ phenomenon has proven to be extremely robust; it occurs in the vast majority of people, and is observed in diverse tasks (Martens \& Wyble, 2010). The most common of these 
tasks is the rapid serial visual presentation (RSVP) paradigm, in which stimuli are presented at a rate of approximately 10 per second. Within a sequential stream of distractor items, two targets are inserted at variable delays from each other (called "lag"). Observers are asked to identify both targets, and the $\mathrm{AB}$ is reflected in their reduced ability to successfully report the second target (T2) when the lag from the first target (T1) is short. Although classic RSVP tasks present all stimuli at a single, central location, the $\mathrm{AB}$ has also been observed in tasks that test performance across the visual field. The oldest and most well-known task to do so is the dwell time (DT) paradigm, pioneered by Duncan, Ward, and Shapiro (1994). In this task, one target appeared at either the left or right of a central fixation dot, while the other target appeared either above or below fixation. Instead of a distractor stream, the targets were each followed by a single pattern mask. As in RSVP, with short delays between targets, the identification of the trailing target was impaired, evidence of the $\mathrm{AB}$.

The universal nature of the $\mathrm{AB}$ suggests that it is the consequence of a general property of cognition. One particularly influential conceptualization of that idea is that the AB reflects what is being perceived consciously, and what is not. In the neural workspace model of conscious access proposed by Dehaene, Sergent, and Changeux (2003; cf. Baars, 1989), conscious awareness is associated with items that mobilize a global, long-distance network in the brain, through which its representation becomes available to various cognitive processes (e.g., verbal report, memory). Items that have not (yet) entered conscious awareness can at most receive local processing, for instance in occipital regions, where basic visual features may be extracted (but not much more). As an item enters the global workspace, initially driven by bottom-up neural activity that eventually 'ignites' the global workspace, the neurons that carry the item's signal inhibit other neurons that might propagate other items, thereby preventing them from entering awareness. 
In terms of the $\mathrm{AB}$, the global workspace model predicts the following. $\mathrm{T} 1$ is logically the first to be selected, to enter the global workspace, and gain conscious access. It then inhibits T2 from subsequently entering the workspace. Therefore, T2 is relegated to lower-level areas (e.g., primary sensory cortices), and cannot reach consciousness. Importantly, this implies an all-ornone situation; if T2 is blinked and denied access to the global workspace, its low-level activity traces cannot be consolidated (episodically) and will inevitably perish, so that the identity of T2 is utterly lost. Sergent and Dehaene (2004) verified this prediction by asking participants to report on the visibility of targets using a continuous response scale. Participants indeed tended towards either indicating no visibility at all for blinked $\mathrm{T} 2 \mathrm{~s}$, or high visibility for $\mathrm{T} 2 \mathrm{~s}$ that were not blinked, with no evidence for cases of partial awareness.

In addition to subjective judgments about perceptual clarity that may be considered unreliable and/or prone to bias (e.g., Hannula, Simons, \& Cohen, 2005), there is also electrophysiological evidence in support of an all-or-none characteristic of the AB. Event-related potential (ERP) studies of the $\mathrm{AB}$ demonstrated that even though early perceptual ERP components (the P1 and N1) survive the $\mathrm{AB}$, the $\mathrm{N} 2 \mathrm{pc}$ and the $\mathrm{P} 3$ are strongly suppressed (Dell'Acqua, Sessa, Jolicœur, \& Robitaille, 2006; Kranczioch, Debener, \& Engel, 2003; Luck, Vogel, \& Shapiro, 1996; Vogel, Luck, \& Shapiro, 1998; Sergent, Baillet, \& Dehaene, 2005). The P3 in particular has been linked to memory consolidation and to the generation of response decisions (Donchin \& Coles, 1988; Kok, 2001; Polich, 2007; Verleger, Jaśkowski, \& Wascher, 2005), exactly the kind of processes that would be expected to suffer from the AB according to the global workspace theory.

One might argue at this point that the typical tasks used to measure the $\mathrm{AB}$ present observers with categorical targets (e.g., letters), for which it is inherently difficult to measure any gradual, partial representation. Either the representation is strong enough for proper 
identification, or it is not. In other words, categorical identification implies having to use a certain threshold function, which naturally produces a binary outcome. To assess whether there is any perceptual evidence surviving the $\mathrm{AB}$, such a categorical threshold must be avoided. It is possible to do so by having observers respond to continuous target properties, such as its color. The deviation in the responses as compared to the target identities can then be assessed and classified in a mixture model of the responses in feature space. In such a model, response errors fall into two distributions, a uniform distribution indicating the guess rate, and a von Mises distribution (for circular response scales) on top of the uniform distribution indicating precision. Starting with the first, if the target does not reach perceptual awareness, responses should not be correlated with the target value. Hence, these random responses should form a uniform, flat distribution, which reflects the guess rate. If the target reaches perceptual awareness, to a degree, there should be a distribution of responses clustering around the target value, the standard deviation of which then shows the precision of the response (Zhang \& Luck, 2008; Bays, Catalao, \& Husain, 2009).

Asplund, Fougnie, Zughni, Martin, and Marois (2014) implemented such continuous reports in a classic RSVP paradigm, by including a T2 whose color the observers had to indicate by using a color wheel. They observed that the $\mathrm{AB}$ was expressed in an exclusive effect on guess rate, not on precision. This means that if the AB occurs, no representation of $\mathrm{T} 2$ remains at all, and any response is simply a guess. If there was no AB, T2 was perceived accurately. There was no evidence for cases in which an impoverished representation of $\mathrm{T} 2$, approximating the actual T2 color, might have been salvaged from the AB. These outcomes thus provide strong evidence for an all-or-none property of the AB.

This is not to say that no target-related information can escape the $\mathrm{AB}$, however. Certain stimulus characteristics do remain accessible when the AB occurs. Notably, semantic information seems to be spared, as the N400 component of the ERP, which reflects such relatively advanced 
stimulus processing (Kutas \& Hillyard, 1980; Kutas \& Federmeier, 2011), is not reduced by the AB (Luck, Vogel, \& Shapiro, 1996; Sergent, Baillet, \& Dehaene, 2005; though see also Giesbrecht, Sy, \& Elliott, 2007). Response-related information may also survive and prime subsequent behavior (Akyürek \& Hommel, 2007). Although such partial information surviving the $\mathrm{AB}$ may seem problematic for all-or-none models, it can be accounted for as the result of ongoing, mostly low-level processing that might proceed without engaging attention or conscious awareness.

How such an account might work in practice can be illustrated by considering one of the most advanced and versatile models of the AB, the eSTST model by Wyble, Bowman, and Nieuwenstein (2009). eSTST was originally based on the two-stage model (Chun \& Potter, 1995) and the idea of types and tokens (Kanwisher, 1987). In the model, types are generic stimulus representations, while tokens are their episodic (integrated) registrations. In eSTST, attention is triggered by bottom-up activation from the incoming stimuli, starting with $\mathrm{T} 1$. When attention is sufficiently elicited, T1 can enter the binding pool, in which types are bound to tokens, and which is situated in working memory. The ongoing binding/consolidation process inhibits attention, which keeps T2 from entering working memory. This inhibition serves the specific purpose of keeping targets apart episodically. Thus, when the AB occurs in this model, T1 is episodically represented, consolidated, and therefore available for report, but T2 is not. However, a type-based representation of $\mathrm{T} 2$ may still be available, which might incorporate semantic as well as response-related properties.

It would thus seem that the case for discrete, all-or-none models of conscious access in the $\mathrm{AB}$ is very strong. Nevertheless, not all theories of conscious awareness assume it is discrete (e.g., Overgaard, Rote, Mouridsen, \& Ramsøy, 2006; Ramsøy, \& Overgaard, 2004; Sandberg, Timmermans, Overgaard, \& Cleeremans, 2010). Furthermore, all of the evidence in favor of 
discrete awareness that was collected to date has come from RSVP studies, in which everything happens at a single location. It is well known that space is special in visual perception, not only because primary visual cortex is organized accordingly (Hubel \& Wiesel, 1974), but also because it seems essential for most episodic object representations to possess a "where" property. However, spatial variability, or the lack thereof, has never been considered much of a critical issue in AB research (e.g., Lunau \& Olivers, 2010), and it has often been tacitly assumed that the $\mathrm{AB}$ is a central phenomenon that is similarly manifest in RSVP as in other tasks such as the DT paradigm (e.g., Martens \& Wyble, 2010).

Nevertheless, this assumption may be questioned, not only for a lack of empirical verification, but also because of previously observed discrepancies between tasks. Consider, for instance, the case of Lag 1 sparing; an AB-related phenomenon in which $\mathrm{T} 2$ performance is atypically high when the targets follow each other directly, without an intervening distractor (Visser, Bischof, \& Di Lollo, 1999). Sparing is related to the temporal integration of the targets into a unified representation (Akyürek et al., 2012; Hommel \& Akyürek, 2005), which may, in turn, underlie an attentional episode. Critically, sparing is abolished when there is a spatial switch between targets (Breitmeyer, Ehrenstein, Pritchard, Hiscock, \& Crisan, 1999; Visser, Zuvic, Bischof, \& Di Lollo, 1999), which suggests that certain, possibly attentional, processes might have changed. Another line of evidence that space is special in the $\mathrm{AB}$ comes from studies that have explicitly looked at the $\mathrm{AB}$ across different locations (Kristjansson \& Nakayama, 2002; Wyble \& Swan, 2015). In these studies, the AB was not abolished across space, but there was a spatial distribution to the effect (with the strongest $\mathrm{AB}$ at the same target location), suggesting that there is some spatial specificity to the $\mathrm{AB}$.

In view of these considerations on the role of space in the $A B$, it is conceivable that even though there may be an attentional limitation across time as well as space, it could be of a 
different nature. Elaborating on eSTST theory (Wyble, Bowman, \& Nieuwenstein, 2009), it may be hypothesized that episodic representations are spatially specific. If this is true, then the 'gateclosing' inhibitory mechanisms that serve to maintain episodic distinctiveness, may not apply when objects are spatially separated. Consequently, the all-or-none characteristic of the $\mathrm{AB}$ may disappear. The current study was designed to test this prediction by applying a continuous report measure in both DT and RSVP paradigms. To preempt the results, the first pair of experiments showed that the $\mathrm{AB}$ was of a gradual rather than a discrete nature in DT tasks. Subsequent experiments showed that the critical factor seemed to be whether spatial overlap between targets was possible or not-whenever it was, the $\mathrm{AB}$ was discrete, and when it was not, the $\mathrm{AB}$ was gradual.

\section{Experiment 1 (Dwell Orientation)}

To assess information loss in the DT paradigm, a continuous target response measure is needed. To this end, line orientation gratings were introduced as targets, and participants were asked to reproduce target orientations at the end of the trial by adjusting the orientation of probe gratings. The response error distributions for different stimulus onset asynchrony (SOA) conditions could thus be modeled, and estimates of precision and guess rate were generated.

\section{Method}

\section{Participants}

Sample size was estimated with G-power (Faul, Erdfelder, Lang, \& Buchner, 2007), using $\alpha=.05$, and $\beta=.2$, as it is commonly done (Lakens, 2013). A priori power computations suggested that 24 participants would be needed to detect medium to large effect sizes (Cohen's $d_{z}$ $=.6$ ), so this number was considered the minimum for each experiment. 30 students participated in Experiment 1, but 5 of them were excluded because of low task performance, having less than 
50 data points in one of the experimental conditions, which is insufficient for reliable model parameter estimates (Bays, Catalao \& Husain, 2009). In the final sample there were thus 25 students (18 females, 7 males) at the University of Groningen, who participated in Experiment 1 in exchange for course credits (mean age $=20.2$, range $=18-24$ ). All participants reported (corrected-to-) normal vision. The study was approved by the ethical committee of the Psychology Department of the University of Groningen (research code 18254-SP). All participants signed an informed consent form prior to participation, and the research was done in accordance with the Declaration of Helsinki (2008).

\section{Apparatus and Stimuli}

Participants were individually seated in dimly-lit sound-attenuated testing cabins, approximately $60 \mathrm{~cm}$ from a 22" CRT screen (Iiyama MA203DT). The resolution was set to 1280 by 1024 pixels, at 16-bit color depth and $100 \mathrm{~Hz}$ refresh rate. Open Sesame 3.2 (Mathôt, Schreij, \& Theeuwes, 2012) with the Expyriment back-end (Krause, \& Lindemann, 2013) was used for trial preparation and data collection, running under the Windows 7 operating system. Responses were collected with a Logitech Attack 3 joystick.

The background color was set to light grey (RGB 128, 128, 128). Target stimuli were orientation gratings with a spatial frequency of 1.8 cycles/degree, and a standard deviation of $.27^{\circ}$, presented within a circle spanning $2.1^{\circ}$ of visual angle (Figure 1c). The orientation of the lines was chosen randomly from any angle between 1 to $180^{\circ}$. Furthermore, the orientation difference between the first and second target was always at least 20 degrees in order to limit the similarity between targets (Figure 1d). The distractors/masks were scrambled, mosaic-patched orientation gratings. These were built as follows. First, 150 orientation gratings, which were identical to target stimuli in terms of low-level stimuli features, were generated. Via Photoshop, each of the orientation gratings was cut into squares of 5 by 5 pixels, which were subsequently 
randomly displaced. Each of the 5 by 5 pixel-squared areas was also randomly rotated. Finally, a mosaic patch was added to the image. As a result, the low-level features of targets and distractors matched, but distractors did not contain any systematic orientation-related information.

\section{Procedure}

Each of the first two blocks consisted of 16 practice trials. Each trial started with a fixation dot, lasting from 600 to $1000 \mathrm{~ms}$. After the fixation dot, T1 appeared at either $1.5^{\circ}$ visual angle above or below of the fixation dot, and remained on screen for $90 \mathrm{~ms}$. At the same time, a distractor appeared on the other side of the fixation dot. After $10 \mathrm{~ms}$ of blank inter-stimulusinterval (ISI), a second array consisting of two distractors was shown at the same location of the first array, for $90 \mathrm{~ms}$. After a brief $(60 \mathrm{~ms})$ or long $(610 \mathrm{~ms})$ ISI, the second target array appeared, such that the lag or SOA was either 250 or $800 \mathrm{~ms}$. T2 appeared at $1.5^{\circ}$ from its edge to either the left or right side of the fixation dot, again for $90 \mathrm{~ms}$. As in the first target array, a distractor was shown on the other side of the fixation dot. The second target array was also followed by a distractor array, which consisted of two masks appearing at the left and right side locations. Target location pairs were randomized but evenly distributed within and across both target arrays. Thus, both target location and temporal onset were unpredictable, providing no information to direct attention to either dimension voluntarily (cf. Denison, Heeger, \& Carrasco, 2017). 500 ms after the offset of the last array, participants were prompted to indicate the orientation of target items in the correct temporal order with a joystick. In the practice trials only, performance feedback was provided. If the target report was within 20 degrees of the actual target orientation, a happy smiley was shown. If the response was more than 20 degrees away from the target orientation, an unhappy smiley was shown. There was no trial-based feedback in experimental trials. However, after each block, feedback about their average performance on each of the two targets was provided to participants. There were 10 experimental blocks in total and there were 
64 trials within each block. Participants were able to have a self-timed break between blocks. The experiment took approximately 75 minutes per participant.

\section{Design and Analysis}

As in virtually all $\mathrm{AB}$ designs, stimulus onset asynchrony (SOA) between $\mathrm{T} 1$ and $\mathrm{T} 2$ was manipulated. There were two conditions in the experiment; a short SOA of $250 \mathrm{~ms}$, and a long SOA of $800 \mathrm{~ms}$, constituting a 2-factorial within-subjects experimental design. Initial analyses were conducted on response accuracy, which reflects how close the response given to each target was to the correct value. Response accuracy was computed with the linear transformation function below:

$$
\mathrm{T}_{\mathrm{acc}}=(\mathrm{c}-\min (|\mathrm{Rv}-\mathrm{Tv}|, 2 \mathrm{c}-|\mathrm{Rv}-\mathrm{Tv}|)) / \mathrm{c}
$$

Where $\mathrm{T}_{\mathrm{acc}}$ is accuracy in percent, $\mathrm{R}_{\mathrm{V}}$ is the response value in degrees, and $\mathrm{T}_{\mathrm{V}}$ is the actual target value in degrees (both $1-180^{\circ}$ ). $\mathrm{c}$ is a constant indicating the maximum difference between any two orientations, which was set at 90 to reflect the range of orientation angles. Accuracy was assessed for both targets. As the $\mathrm{AB}$ is a consequence of the processing of the $\mathrm{T} 1$ on $\mathrm{T} 2$, performance on $\mathrm{T} 2$ was conditionalized on $\mathrm{T} 1$, as is common in AB studies. Specifically, only trials in which $\mathrm{T} 1_{\text {acc }}$ was greater than $75 \%$ were included.

Apart from computing overall response accuracy, the data from both targets were also modeled by applying a standard mixture model, which computes guess rate and precision estimates (Bays, Catalao, \& Husain, 2009). Guess rate reflects the number of responses in which there was no target information apparent (i.e., randomly distributed). Precision reflects the number of cases in which some target information was retained, as evidenced by responses systematically approaching the actual target orientation. The guess rate and precision parameters allow for an assessment of the degree to which target perception occurs in an all-or-none, or in a 
gradual fashion. Thus, by applying the mixture model, underlying sources of error that contribute to overall task accuracy can be determined and analyzed.

To better match the conventional way of describing and visualizing data in $\mathrm{AB}$ studies, the guess rate parameter $P_{g}$ was inverted by using the transformation described by Asplund and colleagues (2014), which subtracts $P_{g}$ from 1 , so that the outcome value indicates maximum probability. Similarly, rather than giving $S D$ for precision, we applied the same linear transformation of degrees to percentages as described above. Through these transformations, higher parameter values reflect better performance, rather than the other way around.

MemToolbox (Suchow, Brady, Fougnie, \& Alvarez, 2013) was used to model the responses given in reference to both targets. Matlab 2018a was used for data pre-processing and modeling, and JASP (version 0.9; JASP Team, 2018) was used for statistical analysis. Bayesian paired-sample T-tests were used to compare $\mathrm{T} 1$ and $\mathrm{T} 2$ report probability, and to compare $\mathrm{T} 1$ as well as T2 guess rate and precision between short and long SOA conditions.

\section{Data availability}

In order to increase replicability, and to provide scientific transparency, the raw data, model outcomes, the analysis scripts, and an example of the experimental tasks were uploaded in a publication package, with the unique identifier $x 5$ dru, to the Open Science Framework (https://osf.io/x5dru).

\section{Results}

Accuracy: On T1 accuracy, Bayesian T-test results showed decisive evidence in favor of the alternative hypothesis, indicating that there was an effect of SOA $\left(B F_{10}=587.7\right)$. T1 accuracy was $69.6 \%$ at short SOA, and increased to $72.4 \%$ at long SOA (Table 1). On T2|T1 accuracy, there was also decisive evidence in favor of the alternative hypothesis, for the existence of an 
bioRxiv preprint doi: https://doi.org/10.1101/769083; this version posted September 14, 2019. The copyright holder for this preprint (which was not certified by peer review) is the author/funder, who has granted bioRxiv a license to display the preprint in perpetuity. It is made available under aCC-BY-NC-ND 4.0 International license.

effect of SOA $\left(B F_{10}>1000\right)$. T2|T1 accuracy averaged $63.3 \%$ at short SOA, compared to $69.7 \%$ at long SOA. 
Table 1. T1 performance in Experiment 1, 2 and 3.

\begin{tabular}{llcccccc}
\hline & & \multicolumn{2}{c}{ T1 Accuracy $(\%)$} & \multicolumn{2}{c}{ T1 Resp Prob (\%) } & \multicolumn{2}{c}{ T1 Precision (\%) } \\
\cline { 3 - 7 } & & Short & Long & Short & Long & Short & Long \\
& & SOA & SOA & SOA & SOA & SOA & SOA \\
\hline \multirow{2}{*}{ Exp. 1 } & MEAN & 69.6 & 72.4 & 58.4 & 65.6 & 81.6 & 81.9 \\
& $S E M$ & 2.2 & 2.2 & 5.7 & 4.7 & 2.6 & 1.1 \\
\hline Exp. 2 & $M E A N$ & 90.1 & 90.7 & 92.1 & 92.7 & 90.8 & 91.2 \\
& $S E M$ & 1.2 & 1.2 & 2.5 & 2.6 & 0.3 & 0.3 \\
\hline Exp. 3 & $M E A N$ & 77.3 & 79.5 & 76.7 & 80.2 & 81.0 & 82.4 \\
& SEM & 9.5 & 9.4 & 3.9 & 3.7 & 1.5 & 1.1 \\
\hline
\end{tabular}

SEM = Standard Error of the Mean, Exp. = Experiment, $T 1$ Resp Prob $=$ T1 Response

Probability

Guess rate and precision: Bayesian test results revealed evidence against the effect of SOA on $\mathrm{T} 1$ response probability and precision $\left(B F_{10}<.9\right)$. Furthermore, substantial evidence was observed in favor of the null hypothesis of the SOA effect on $\mathrm{T} 2 \mid \mathrm{T} 1$ response probability $\left(B F_{10}<\right.$ .2). There was, however, substantial evidence in favor of the effect of SOA on T2 precision $\left(B F_{10}\right.$ $=6.6) . \mathrm{T} 2 \mid \mathrm{T} 1$ precision averaged $76.8 \%$ at the long SOA compared to $67.6 \%$ at the short SOA.

\section{Discussion}

The results were unequivocal: In the DT paradigm, the $\mathrm{AB}$ is expressed not through an all-or-none (guess rate) effect, but is rather of a gradual nature. The precision of the T2 representation suffers from $\mathrm{T} 1$ processing, but the representation is not completely lost. This finding stands in contrast to previous findings by Asplund et al. (2014), who showed the exact opposite pattern (i.e., all-or-none) in continuous color report in an RSVP paradigm. The current outcome thus suggests that there might be something fundamentally different in the nature of the $\mathrm{AB}$ as observed in DT and in RSVP tasks. Alternatively, the divergent results might be due to the use of stimulus material (gratings vs color). A subsequent experiment was set up to determine this. 


\section{Experiment 2 (Dwell Color)}

The motivation of Experiment 2 was to replicate the results of Experiment 1 using color instead of orientation stimuli. Thereby it can be tested whether the present results might be uniquely due to the processing of orientation features, or whether the findings of Experiment 1 can be generalized to the domain of color features. This is particularly important because of the contrasting findings of Asplund et al. (2014), who also used colors.

\section{Method}

\section{Participants}

26 new students (22 females, 4 males) participated in the study in exchange for course credits (mean age $=19.9$, range $=18-28)$.

\section{Apparatus, Stimuli, and Procedure}

Experiment 2 was identical to Experiment 1 with the following changes. Target stimuli were circles filled with colors from the HSL color spectrum. Saturation was set to $100 \%$ and luminance was set to $50 \%$. Hue was chosen randomly from the HLS color wheel. The task was to reproduce the exact color of the targets from a color wheel and responses were collected with a standard mouse. Because the maximum error is $180^{\circ}$ in color reproduction tasks, unlike that of line orientation, the constant $\mathrm{c}$ in the accuracy transformation function (see above) was set to 180 instead of 90 . In view of the robust effects, and in order to counteract possible fatigue, there were now 8 blocks with 64 trials each, which meant that the experiment lasted approximately one hour.

\section{Results}

Accuracy: Strong evidence was observed for an influence of SOA on T1 and T2|T1 accuracy $\left(B F_{10}=64.3 ; B F_{10}=61.5\right.$, respectively $)$. The effect size appeared to be modest: T1 accuracy was 
$90.1 \%$ at short SOA and increased to $90.7 \%$ at long SOA. T2|T1 accuracy averaged $88.5 \%$ at short SOA and increased to $89.7 \%$ at long SOA.

Guess rate and precision: The SOA effect on T1 was not apparent from the model-based results. There was substantial evidence on $\mathrm{T} 1$ response probability and anecdotal evidence on $\mathrm{T} 1$ precision in favor of the null hypothesis of the effect of SOA $\left(B F_{10}<1.0\right)$. Additionally, anecdotal evidence in favor of the null hypothesis that SOA did not influence T2|T1 response probability was found $\left(B F_{10}<.4\right)$. However, strong evidence in favor of the effect of SOA on $\mathrm{T} 2 \mid \mathrm{T} 1$ precision existed $\left(B F_{10}=17.3\right)$. T2|T1 precision averaged $90.4 \%$ at long SOA compared to $89.6 \%$ at short SOA.

\section{Discussion}

The results of Experiment 2 replicated those of Experiment 1, providing further evidence that reduced $\mathrm{T} 2 \mid \mathrm{T} 1$ precision, rather than increased guess rate, underlies the $\mathrm{AB}$ at short $\mathrm{SOA}$ in the DT paradigm. It must be noted that $\mathrm{AB}$ magnitude was small in the present study. This may be related to the speed at which color and orientation information can be consolidated in working memory, which has been estimated at only 50-67 ms for color targets, compared to $117 \mathrm{~ms}$ for orientation targets (Vogel, Woodman, \& Luck, 2006; Woodman, \& Vogel, 2008). Despite the small $\mathrm{AB}$, however, the statistical evidence was highly robust. Not only was there strong evidence for an effect of SOA on accuracy, but also on precision, as well as evidence against an effect of SOA on guess rate. All of these point in the same direction and confirm that the nature of the $\mathrm{AB}$ in the current paradigm is gradual; there is a loss of quality in the representation of a 'blinked' color target, but it is not completely missed, as was also observed for orientation in the previous experiment.

\section{Experiment 3 (Central RSVP Orientation)}


Experiment 1 and 2 showed a clear dissociation with the existing literature, in which the $\mathrm{AB}$ has been characterized exclusively as an all-or-none phenomenon (e.g., Asplund et al., 2014; Sergent \& Dehaene, 2004). Given that this discrepancy does not appear to be due to the nature of the stimuli (orientation or color), the results suggest that there might be a fundamental, underlying difference in the performance deficits observed in DT and RSVP tasks, even though both paradigms elicit the typical $\mathrm{AB}$. The gradual nature of the $\mathrm{AB}$ presently observed could be a result of task differences between DT and RSVP paradigms that change the way that temporal attention operates. To verify that attentional allocation is indeed different in the DT and RSVP tasks, it is essential to first replicate previous reports of guess rate effects in RSVP, which was the aim of Experiment 3.

\section{Method}

\section{Participants}

26 new students participated in the study for course credit. One of them was excluded from the analysis, following the same criteria as in Experiment 1 (16 females, 9 males; mean age $=19.9$, range $=18-23)$.

\section{Stimuli, Apparatus, and Procedure}

Experiment 3 was identical to Experiment 1 with the following changes. A classical RSVP design was applied. Each trial started with a fixation dot ranging from 300 to $500 \mathrm{~ms}$. After the fixation dot, an RSVP consisting of 18 items started (2 targets and 16 distractors). Targets and distractors were identical to Experiment 1. Each item in the stream was shown in the center of the screen for $90 \mathrm{~ms}$ and succeeding items in the RSVP were separated with $10 \mathrm{~ms}$ ISI. T1 was the $5^{\text {th }}$ to $8^{\text {th }}$ item in the stream, which was randomized but evenly distributed. The number of distractors between targets differed depending on the experimental manipulation. There were two distractors $(\mathrm{SOA}=300 \mathrm{~ms})$ between $\mathrm{T} 1$ and $\mathrm{T} 2$ in the short SOA condition and 7 
distractors $(\mathrm{SOA}=800 \mathrm{~ms})$ in the long SOA condition. There was a $500 \mathrm{~ms}$ interval after the stream ended, prior to the response prompts. As before, the task was to reproduce the orientations of the targets in the correct temporal order (Figure 4a). There were 8 experimental blocks, and each block consisted of 60 trials.

\section{Results}

Accuracy: Decisive evidence was observed of the effect of SOA on T1 accuracy $\left(B F_{10}>1000\right)$. T1 accuracy was $77.3 \%$ at short SOA and $79.5 \%$ at long SOA. Decisive evidence was also obtained for an SOA effect on T2|T1 accuracy $\left(B F_{10}>1000\right)$. T2|T1 accuracy was $63 \%$ at short SOA, and $76.3 \%$ at long SOA.

Guess rate and precision: Anecdotal evidence of the SOA effect on T1 response probability was observed $\left(B F_{10}=1.6\right)$. $\mathrm{T} 1$ response probability was $76.7 \%$ at short SOA, and increased slightly to $80.2 \%$ at long SOA. There was no evidence in favor of the effect of SOA on $\mathrm{T} 1$ precision $\left(B F_{10}<\right.$ 1.0). In contrast, there was decisive evidence in favor of the effect of SOA on T2|T1 response probability $\left(B F_{10}=495.7\right)$. T2|T1 response probability was $50.4 \%$ at short SOA compared to $79.8 \%$ at long SOA. Substantial evidence existed in favor of the null hypothesis that SOA did not have an effect on T2|T1 precision $\left(B F_{10}<.4\right)$.

\section{Discussion}

The experiment replicated the findings of Asplund et al. (2014) for line orientations and provided evidence supporting major models of the AB, such as the eSTST theory (Wyble, Bowman, \& Nieuwenstein, 2009), which holds that T2 cannot bind to a token during the AB, and is consequently lost altogether. There was no evidence for a precision effect, such as observed in Experiment 1 and 2.

\section{Experiment 4 (Lateral RSVP Orientation)}


Possibly the most conspicuous difference between the cognitive processing required in DT and RSVP paradigms is that locations change in the former paradigm, but not the latter. Spatial locations are special when it comes to attentional processing. For instance, a locationspecific cue will modulate the early $\mathrm{P} 1$ and $\mathrm{N} 1$ components of the event-related potential (Hillyard \& Münte, 1984; Luck et al., 1994), while a feature-based cue has a noticeably later locus (Anllo-Vento \& Hillyard, 1996; Hillyard \& Münte, 1984). Furthermore, it has long been known that the Lag 1 sparing phenomenon that often accompanies the $\mathrm{AB}$ is prevented whenever a spatial switch occurs (Visser, Bischof, \& Di Lollo, 1999). It is thus conceivable that a spatial switch may similarly change attentional processing in such a way that overall performance remains similar, but the underlying process does not. To investigate if the nature of the $A B$ changes when targets occur in more than a single spatial location, a second stimulus stream was added in Experiment 4. If having a single spatial location is the critical factor in producing an allor-none $A B$ effect, then this should be abolished in the present experiment, and a gradual (i.e., precision) effect should be observed.

\section{Method}

\section{Participants}

32 new students participated in the experiment in exchange for course credits or monetary compensation of 12 Euros. 8 of them were excluded from the analysis because of poor performance, so that 24 remained in the final sample ( 8 females, 16 males; mean age $=19.9$, range $=18-23)$

\section{Stimuli, Apparatus, and Procedure}

Experiment 4 was identical to Experiment 3 with the following changes. The fixation dot remained at the center of the screen from the start of the trial until the end to help participants to keep their gaze at the center. After the first fixation period (300 to $500 \mathrm{~ms}$ ), two streams on the 
right and left side of the fixation dot started, at a lateral distance of $1.5^{\circ}$ degrees of visual angle. Participants were instructed to keep fixating the central dot. T1 appeared in either the left or right stream, and again as the $5^{\text {th }}$ to $8^{\text {th }}$ item. The spatial position of T1 was randomized but evenly distributed. Apart from the usual lag between T1 and T2 (300 and 800 ms), the spatial position of T2 was also manipulated. Target locations were identical in the same location condition (e.g., T1 on the left, and T2 also on the left) and they were different in the different location condition (e.g., T1 on the right and T2 on the left, as shown in Figure 4b).

\section{Design and Analysis}

A 2 (SOA; short or long) by 2 (Position; same or different) design was used to investigate how spatial target locations influence identification performance. A Bayesian Repeated Measures ANOVA was run to test the main effect of SOA, Location and the interaction effect of both on $\mathrm{T} 1$ and T2|T1 accuracy. The best model (highest BF value) was used to interpret the outcomes. Corrections were done for further post-hoc tests as described by Westfall, Johnson, and Utts (1997).

A Bayesian Paired Sample T-test was used for testing the main effects of SOA and Location, and a Bayesian Repeated Measures ANOVA was used to investigate the interaction of SOA and Location on $\mathrm{T} 1$ response probability, $\mathrm{T} 1$ precision, $\mathrm{T} 2 \mid \mathrm{T} 1$ response probability and $\mathrm{T} 2$ |T1 precision. Corrections were done for further post-hoc tests of the interactions. These tests were run separately because model predictions of guess rate and precision can differ slightly depending on the trials that are pooled within.

\section{Results}

Accuracy: Bayesian Repeated Measures ANOVA results showed that the best model of T1 accuracy included the main effects of SOA and Location $\left(B F_{10}=913.6\right)$. T1 accuracy averaged $76.7 \%$ at short SOA and increased to $77.7 \%$ at long SOA $\left(B F_{10}=5.7\right)$. In addition, T1 accuracy 
was $76.4 \%$ when the targets appeared at the same location, compared to $78.0 \%$ when the location was different $\left(B F_{10}=195.8\right)$. The best model explaining $\mathrm{T} 2 \mid \mathrm{T} 1$ accuracy included only the main effect of SOA $\left(B F_{10}>1000\right)$. T2|T1 accuracy averaged $68.6 \%$ at short SOA and $75.1 \%$ at long $\operatorname{SOA}\left(B F_{10}>1000\right)$. 
Table 2. T1 performance in Experiment $4 \& 5$.

\begin{tabular}{|c|c|c|c|c|c|c|}
\hline & & & Experim & & Experi & ent 5 \\
\hline & & & $M E A N$ & SEM & $\begin{array}{c}M E A \\
N\end{array}$ & SEM \\
\hline SOA & Short & T1 Accuracy (\%) & 76.6 & 1.2 & 69.8 & 2.0 \\
\hline & & T1 Resp. Prob. (\%) & 72.9 & 0.6 & 57.5 & 5.4 \\
\hline & & T1 Precision (\%) & 83.2 & 2.7 & 82.1 & 1.0 \\
\hline & Long & T1 Accuracy (\%) & 77.7 & 1.2 & 73.8 & 1.8 \\
\hline & & T1 Resp. Prob. (\%) & 76.3 & 3.4 & 69.1 & 4.4 \\
\hline & & T1 Precision (\%) & 83.2 & 0.6 & 81.2 & 1.2 \\
\hline LOCATION & Same & T1 Accuracy (\%) & 76.4 & 1.3 & 70.9 & 1.9 \\
\hline & & T1 Resp. Prob. (\%) & 72.5 & 3.6 & 60.2 & 5.1 \\
\hline & & T1 Precision (\%) & 83.1 & 0.6 & 81.7 & 0.9 \\
\hline & Different & T1 Accuracy (\%) & 78.0 & 1.2 & 72.7 & 1.8 \\
\hline & & T1 Resp. Prob. (\%) & 76.5 & 3.1 & 66.3 & 4.9 \\
\hline & & T1 Precision (\%) & 83.4 & 0.5 & 81.7 & 1.3 \\
\hline SOA*LOCATI & Short X & T1 Accuracy (\%) & 75.5 & 1.4 & 68.0 & 2.1 \\
\hline $\mathbf{O N}$ & Same & T1 Resp. Prob. (\%) & 70.0 & 3.7 & 52.9 & 5.9 \\
\hline & & T1 Precision (\%) & 83.3 & 0.6 & 82.8 & 1.2 \\
\hline & Short X & T1 Accuracy (\%) & 77.8 & 1.1 & 71.5 & 1.9 \\
\hline & Different & T1 Resp. Prob. (\%) & 76.9 & 3.1 & 62.7 & 4.9 \\
\hline & & T1 Precision (\%) & 83.0 & 0.8 & 81.4 & 1.0 \\
\hline & Long X & T1 Accuracy (\%) & 77.7 & 1.2 & 73.8 & 1.8 \\
\hline & Same & T1 Resp. Prob. (\%) & 75.5 & 3.5 & 68.2 & 4.2 \\
\hline & & T1 Precision (\%) & 83.0 & 0.8 & 80.1 & 1.0 \\
\hline & Long X & T1 Accuracy (\%) & 78.3 & 1.3 & 73.8 & 1.8 \\
\hline & Different & T1 Resp. Prob. (\%) & 77.5 & 3.4 & 71.2 & 4.9 \\
\hline & & T1 Precision (\%) & 83.5 & 0.6 & 81.2 & 1.5 \\
\hline
\end{tabular}

$S E M=$ Standard Error of the Mean, Exp. $=$ Experiment, $T 1$ Resp Prob $=$ T1 Response

Probability

Guess rate and precision: Substantial evidence was observed in favor of the alternative hypothesis that the main effect of SOA and Location influenced $\mathrm{T} 1$ response probability $\left(B F_{10}=\right.$ $6.0 ; B F_{10}=4.0$, respectively). $\mathrm{T} 1$ response probability averaged $72.9 \%$ at short SOA, and increased to $76.3 \%$ at long SOA. Also, T1 response probability averaged $72.5 \%$ at the same location, compared to $76.5 \%$ at different locations. Strong evidence in favor of the interaction of SOA and Location on $\mathrm{T} 1$ response probability was also observed $\left(B F_{10}=17.5\right)$. $\mathrm{T} 1$ response probability averaged $70.0 \%$ at short SOA and at the same location, and increased to $75.5 \%$ at the 
long SOA and at the same location $\left(B F_{10}=37.7\right)$. T1 response probability was $76.9 \%$ at the short SOA and at different locations, which was greater than at the short SOA and at the same location $\left(B F_{10}=5.7\right)$. T1 precision was not affected by SOA, position, or their interaction $\left(B F_{10}<.3\right)$.

There was strong evidence of a main effect of SOA on T2|T1 response probability $\left(B F_{10}=\right.$ 56.4). T2|T1 response probability was $57.7 \%$ at short SOA, compared to $72.3 \%$ at long SOA. There was no evidence that location influenced $\mathrm{T} 2 \mid \mathrm{T} 1$ response probability $\left(B F_{10}<.4\right)$. However, there was strong evidence supporting the hypothesis that the interaction of SOA and location influenced $\mathrm{T} 2 \mid \mathrm{T} 1$ response probability $\left(B F_{10}=15.1\right)$. $\mathrm{T} 2 \mid \mathrm{T} 1$ response probability was $59.6 \%$ at the short SOA and at the same location, compared to $73.7 \%$ at long SOA and in the same location condition $\left(B F_{10}=5.6\right)$. In addition, T2|T1 response probability was averaged $70.9 \%$ at the long SOA and different location condition and decreased to $56.6 \%$ at the short SOA and different location condition $\left(B F_{10}=13.0\right)$. With regard to $\mathrm{T} 2 \mid \mathrm{T} 1$ precision, there was no evidence for an effect of SOA $\left(B F_{10}<.3\right)$, Location $\left(B F_{10}<.3\right)$, nor their interaction $\left(B F_{10}<.1\right)$.

\section{Discussion}

The results showed that spatial switching did not modulate T2 report probability or T2|T1 precision. As in Experiment 3, which used the traditional single-stream RSVP paradigm, the AB was presently expressed in guess rates only, suggesting that an all-or-none mechanism was at work. The outcomes of Experiment 4 make it unlikely that the gradual nature of the $\mathrm{AB}$ that was observed in the current DT experiments was due to the mere introduction of a spatial switch.

\section{Experiment 5 (Lateral Dwell Orientation)}

Experiment 4 showed no evidence of a T2|T1 precision effect. With that finding, only two possible causes for the difference between the gradual and discrete nature of the $\mathrm{AB}$ remain viable. The first obvious factor is the presence of the distractor stream in RSVP. While it is 
common to assume that the first distractor after a target item is a sufficient mask in the context of the $\mathrm{AB}$, which has been observed with minimal 4-dot masking (Dell'Acqua, Pascali, Jolicœur, \& Sessa, 2003), and even without any T1 mask (Visser, 2007), there may be some higher-level property of an ongoing stream that triggers a different attentional processing mechanism. The second factor is a bit more subtle. Although the dual-stream RSVP in Experiment 4 introduced variability in spatial location, similar to the DT paradigm, the spatial dynamics were not fully identical. Specifically, in the dual stream RSVP, but not in the DT paradigm, the location of the targets could be the same. This probability of spatial overlap may trigger attentional mechanisms that deal with spatially-specific competition between the targets.

To decisively identify the cause of the discrepancy between the gradual and discrete nature of the $\mathrm{AB}$, the logic of Experiment 1 was revisited. Following the original DT implementation in Experiment 1, there was no possibility that targets shared the same location, and there was no stream of distractors. In Experiment 5, we changed one of these parameters; the design was modified such that targets could now share the same location. If this change causes the gradual $\mathrm{AB}$ effect, as observed in Experiment 1, to change into a discrete effect, then spatial overlap between target locations must be the critical factor. If a gradual effect still occurs, then the absence of a distractor stream must be the causal factor.

\section{Method}

\section{Participants}

26 new students participated in the study in exchange for course credit or monetary reward of 12 euros. Two participants were excluded from the analysis because of low performance, so that 24 remained (17 females, 7 males; mean age $=23.8$, range $=19-32$ ).

\section{Procedure and design}


Experiment 5 was identical to Experiment 1, but with one exception. Instead of T1 appearing on the locations below or above the center of the screen, it now appeared on the locations to the left and right, which were also used for $\mathrm{T} 2$, as before, thereby creating the possibility of spatial overlap (Figure 4c). As in Experiment 4, both SOA and Location (same or different) were considered in the analysis.

\section{Results}

Accuracy: Bayesian Repeated measures analysis was applied to assess the main effects of SOA and Location, as well as their interaction, on T1 and T2|T1 accuracy. The best model of T1 accuracy comprised the main effects of SOA and Location as well as their interaction $\left(B F_{10}>\right.$ 1000). T1 accuracy averaged $69.8 \%$ at short SOA and increased to $73.7 \%$ at long SOA $\left(B F_{10}>\right.$ 1000). Moreover, T1 accuracy averaged $70.9 \%$ at the same location, compared to $72.7 \%$ at the other location $\left(B F_{10}=22.7\right)$. In terms of the interaction of SOA and Location, T1 accuracy averaged $68 \%$ at short SOA at the same location, which was lower than at the long SOA and the same location $\left(73.8 \% ; B F_{10}>1000\right)$, and lower than at short SOA at the different location $\left(71.5 \% ; B F_{10}=640.4\right)$. Furthermore, T1 accuracy at short SOA and different location was $71.5 \%$, compared to $73.8 \%$ at long SOA and different Location condition $\left(B F_{10}=19.3\right)$.

The best model of T2|T1 accuracy comprised only the main effects of SOA and Location $\left(B F_{10}>1000\right)$. T2|T1 accuracy was $63.7 \%$ at short SOA and increased to $72.6 \%$ at long SOA $\left(B F_{10}>1000\right)$. Similarly, T2|T1 accuracy was $65.6 \%$ at different target locations, compared to $70.7 \%$ at the same target locations $\left(B F_{10}>1000\right)$.

Guess rate and precision: Decisive evidence was observed in favor of the main effect of SOA on $\mathrm{T} 1$ response probability $\left(B F_{10}>1000\right)$. T1 response probability averaged $57.5 \%$ at short SOA and increased to $69.1 \%$ at long SOA. There was substantial evidence that Location influenced T1 response probability $\left(B F_{10}=6.8\right)$. T1 response probability averaged $60.2 \%$ at the same location, 
which was lower than the $66.3 \%$ at the other location. The interaction of SOA and Location on T1 response probability was also reliable $\left(B F_{10}>1000\right)$. T1 response probability averaged $52.9 \%$ at short SOA and the same location, less than the $62.7 \%$ at short SOA and the different location $\left(B F_{10}=962.0\right)$. Furthermore, T1 response probability at long SOA and at the different location $($ mean $=71.2 \%)$ was higher than at short SOA and different location $\left(B F_{10}=5.6\right)$. However, SOA did not influence $\mathrm{T} 1$ precision $\left(B F_{10}<.4\right)$. There was also no evidence in favor of the main effect of Location on $\mathrm{T} 1$ precision $\left(B F_{10}<.3\right)$. Finally, no evidence was found in favor of the hypothesis that the interaction of SOA and Location influenced T1 precision $\left(B F_{10}<.1\right)$.

There was strong evidence in favor of the main effect of SOA and decisive evidence in favor of the main effect of location on T2|T1 response probability $\left(B F_{10}=24.1 ; B F_{10}>1000\right.$, respectively). T2|T1 response probability was $43.9 \%$ at short SOA and increased to $63.9 \%$ at long SOA. Similarly, T2|T1 response probability averaged $43.8 \%$ at different locations and increased to $60.3 \%$ at same locations. There was also evidence in favor of the interaction of SOA and location on $\mathrm{T} 2 \mid \mathrm{T} 1$ response probability $\left(B F_{10}=88.9\right)$. T2 $\mid \mathrm{T} 1$ response probability was $54.2 \%$ at the short SOA and at the same location, compared to $74.6 \%$ at long SOA and in the same location condition $\left(B F_{10}=11.5\right)$. Moreover, T2|T1 response probability was better in the long SOA and same location condition compared to the long SOA and different location condition $\left(56.1 \%, B F_{10}\right.$ $=82.7)$. With regard to precision, the Bayesian Paired Sample T-Test revealed substantial evidence in favor of the null hypothesis that SOA did not influence T2|T1 precision $\left(B F_{10}=.2\right)$. There was anecdotal evidence supporting the null hypothesis that Location did not affect T2|T1 precision $\left(B F_{10}=.4\right)$. The Bayesian ANOVA also showed decisive evidence against the interaction effect of SOA and Location on T2|T1 precision $\left(B F_{10}<.1\right)$.

\section{Discussion}


The outcome of Experiment 5 was clear: In this DT task with shared target locations, there was no gradual AB, but a discrete one. Neither SOA nor actual location overlap affected precision, while guess rate was influenced by both. By logical inference, this means that the presence of a stream of distractors is not the causal factor behind the previously observed differences; single target masks presently caused a discrete AB. It thus seems instead that spatially specific target competition underlies the discrete AB. The outcomes of Experiment 5 also suggested that there was a direct location-based trade-off between T1 and T2 processing. T1 performance was better when target locations were different, while T2 performance was better when target locations were the same, which was reflected in both accuracy and response probability.

\section{General Discussion}

As the title of the present article suggests, the $\mathrm{AB}$ can have two very different faces: Gradual and discrete. In Experiments 1 and 2, which were classic DT tasks, the AB exclusively affected the representational precision of orientation and color features, and not the guess rate. Experiments 3 and 4 showed that the opposite was true for RSVP tasks. The AB was expressed in elevated guess rates only. Finally, in Experiment 5, which implemented a modified DT paradigm in which targets could appear at the same location, a guess rate effect was also observed. Taken together, the results show a double dissociation between cases of gradual and discrete blinks. These different cases seem governed by the possibility of spatial overlap between targets. Such overlap triggers a specific attentional mechanism that causes all traces of blinked targets to perish, presumably in an attempt to maintain episodic distinctiveness. The current outcomes have several implications for theories of (temporal) attention and conscious awareness, which will be discussed below.

\section{Temporal attention}


The current results reinforce the notion that some attentional deficit, an $\mathrm{AB}$, occurs across time as well as space, and in this sense it remains a general limit on our cognitive abilities (cf. Kristjansson \& Nakayama, 2002; Wyble \& Swan, 2015). The urgent question raised by the current study is why that limit is of a different nature dependent on the potential for spatial overlap of the target stimuli. One clue may be provided by the observation that in the present experiments, if there were trials in the task in which targets shared the same location, a gradual blink did not occur even when targets actually appeared in different locations, (recall that trial order was random and target locations were thus unpredictable). This suggests a certain strategic element (cf. Taatgen, Juvina, Schipper, Borst, \& Martens, 2009), even though it is probably fully implicit: If there is a risk that targets might occupy the same location, a protective attentional gating mechanism is activated that prevents $\mathrm{T} 2$ from entering the advanced processing stage occupied by $\mathrm{T} 1$.

The existence of such a protective inhibitory mechanism is predicted explicitly by the eSTST model of the AB (Wyble, Bowman, \& Nieuwenstein, 2009), where it serves to maintain the episodic distinctiveness of the targets. This is an appealing functional justification that is highly compatible with the current results. In eSTST, attention is thought to be inhibited by the process of working memory encoding, an idea that is similarly implemented in other AB models (e.g., Olivers \& Meeter, 2008), and which is very reminiscent of the workings of the global workspace model by Dehaene and colleagues (Dehaene, Sergent, \& Changeux, 2003; Sergent, Baillet, \& Dehaene, 2005). However, the current outcomes show that this inhibition, of which the hallmark feature is the all-or-none characteristic of the $\mathrm{AB}$, is engaged strategically, and only when targets might share the same location. With regard to the eSTST model, this implies that the binding process that is hypothesized to take place in working memory, in which types are bound to tokens, hinges not only on the timestamp of the stimuli, but also their location. Binding 
of T2 can apparently proceed, albeit imperfectly, as long as there is no competition between target representations for the same location. The idea that location is special is reinforced by previous work by Asplund and colleagues (2014), who showed that featural dissociations between targets are apparently not enough to preserve episodic distinctiveness: They observed a discrete $\mathrm{AB}$ with clearly different $\mathrm{T} 1$ and $\mathrm{T} 2$ stimuli (a black/white and a color square, respectively), suggesting that the attentional gating mechanism was in full effect.

The special status of target location may reflect the primary spatial (retinotopic) organization of visual cortex, particularly in earlier areas (Hubel \& Wiesel, 1974). Electrophysiological studies have also consistently shown that space drives attention more directly than featural properties do (Anllo-Vento \& Hillyard, 1996; Hillyard \& Münte, 1984; Luck et al., 1994). It is therefore not surprising that influential models of attention have often assumed that space is a primary dimension, of a more fundamental nature than other features (such as color or orientation). For instance, in the Guided Search model (Wolfe, 1994), attention is driven by an activation map that places saliency signals coming from different feature dimensions on spatial coordinates. Similar spatial maps are implemented in other influential models of attention as well (e.g., Treisman \&, Gelade, 1980; Itti \& Koch, 2000; Bundesen, Habekost, \& Kyllingsbæk, 2005).

The current results strongly suggest that it is time to incorporate the spatial dimension in models of temporal attention and the $\mathrm{AB}$; not just as a dimension across which blink strength might vary, but also one in which competitive interactions can occur, and commensurate mechanisms are engaged, when multiple targets appear at the same location. Specifically, location might very well be the primary index of feature binding, which accordingly needs to be shielded from interference to preserve unambiguous access to the target representation (cf. episodic distinctiveness, Wyble, Bowman, \& Nieuwenstein, 2009). Such shielding might be 
conceptualized as inhibition originating from working memory, or as an attentional gate, triggered by the binding or consolidation of the privileged (first) target item. Note that such an interference dynamic is yet implicit in models of spatial attention also, as they are typically concerned with single scenes, not successive events (though see also Petersen, Kyllingsbæk, \& Bundesen, 2012).

With regard to attention, a final note must be made about the fate of targets that suffer from a gradual $\mathrm{AB}$, as these do not survive unscathed. The quality of their representations is markedly reduced, which indicates that even when location-feature binding can proceed unambiguously, there is a rate limitation that applies to the overall process. Thus, even if these T2s do manage to creep into the binding pool (or workspace, second stage, etc.), due to the lack of attentional gating, T1s already dominate within by virtue of their earlier arrival. Consequently, the T2 representations still cannot be processed with equal vigor, and become or remain imperfect. This account is compatible with the idea that the $\mathrm{AB}$ is due to target competition in visual working memory, as previously proposed by Shapiro, Raymond, and Arnell (1994). It is conceivable that such competitive interactions are related to the process of (short-term) memory consolidation (Jolicœur \& Dell'Acqua, 1998), implicating that the consolidation process need not necessarily affect attention in an all-or-none fashion either (Ricker \& Hardman, 2017).

\section{Conscious awareness}

The current finding that the $\mathrm{AB}$ can be expressed both as a discrete, all-or-none, and as a gradual phenomenon has clear implications for theories of conscious awareness that put discrete selection during the $\mathrm{AB}$ at the center of that state of mind (Asplund et al, 2014; Dehaene, Sergent, \& Changeux, 2003; Sergent \& Dehaene, 2004; Sergent, Baillet, \& Dehaene, 2005). Clearly, a discrete AB is not necessarily typical for the nature of awareness, if observers are able to report at least partial information about blinked targets in the DT paradigm. Rather, that 
discrete property seems more due to a location-specific shielding mechanism that is presumably attentional in nature. It seems strenuous to suppose that awareness should be similarly locationspecific, or that different global workspaces may be instantiated for different locations. In other words, a location-specific mechanism is hard to reconcile with a fundamental property of awareness, but is not out of place as a characteristic of attentional selection.

It must be stressed that the current results do not falsify the concept of a global workspace itself. The idea that an item in the center of awareness propagates through a large functional network, by which it claims a certain exclusivity at the expense of other pending items, is if anything strengthened by the currently observed blinks in both DT and RSVP tasks. It is the inhibitory gating mechanism, the binary choice between perceiving something and missing something completely, that is shown to be less universal than previously believed (i.e., it is location-specific). It may be hypothesized that even though conscious awareness may well be instantiated through a global neuronal workspace, this state of mind is distinct from the attentional mechanisms that deliver its contents. To take the nature of the $\mathrm{AB}$ to reflect on the nature of conscious awareness may thus be an over-generalization.

The hypothesis that awareness might be gradual has previously been advanced, mainly on the basis of visual masking experiments (Overgaard, Rote, Mouridsen, \& Ramsøy, 2006; Ramsøy, \& Overgaard, 2004; Sandberg, Timmermans, Overgaard, \& Cleeremans, 2010). On the one hand, this claim is compatible with the current findings, and proves that gradual awareness is not unique to the present paradigms. On the other hand, the current results also suggest that awareness should not be seen as exclusively gradual either. Rather, the nature of awareness seems to be adaptive, and to depend on the task and the conditions it imposes, such that either gradual or discrete awareness may arise in the same brain.

\section{Open questions}


The outcomes of the current study spawn a number of issues that may further elucidate the nature of attentional gating and conscious awareness in the $\mathrm{AB}$. First, in the present experiments, the nature of the $\mathrm{AB}$ changed dependent on whether targets could appear at the same location, or not. As argued above, location may be special, but location-based information that is registered at earlier levels of the visual processing stream may also be superseded by more comprehensive conceptual information at higher levels. In particular, whether an item is part of a larger figure, or an object, may supplement the raw spatial coordinates. As such, it would be interesting to examine whether attentional gating occurs at the object level as well.

Second, since awareness is presumably modality-unspecific, it would seem worthwhile to investigate the gating function in other modalities, such as hearing. Auditory blinks certainly occur (e.g., Duncan, Martens, \& Ward, 1997), but space is not as primary to audition as it is to vision. In audition, time may be more important (Näätänen \& Winkler, 1999). It thus remains to be seen whether and when attentional gating occurs in the former modality, or whether the $\mathrm{AB}$ is always gradual without location-based interference between targets.

Third, one might wonder about the majority of the items in the stream that make up an RSVP; the distractors. In the present experiments, the presence or absence of the stream did not affect the nature of the $\mathrm{AB}$. However, some location-specific modulation of performance did occur in Experiment 5, which was not apparent in the RSVP tasks. Although this might be a chance finding that should first be replicated, it might also point to a unique effect of the stream itself. In relation to electrophysiological measures of hidden knowledge, the stream has been considered an important ingredient in placing the targets and distractors at the edge of perceptual awareness, such that only the most salient can break through (i.e., those that are recognized as familiar; Bowman et al., 2013). 
Fourth, the magnitude of the $\mathrm{AB}$ has been related to the 'investment' put into T1 (Olivers \& Nieuwenhuis, 2006; Shapiro et al., 2006; Taatgen et al., 2009; Wierda et al., 2012). In temporal attention models, this is directly related to the strength of inhibition that occurs after an observer encounters the target. The attentional gate is expected to shut more vigorously when T1 is strongly attended (Olivers \& Meeter, 2008; Wyble, Bowman, \& Nieuwenstein, 2009). It will be interesting to examine whether a gradual $\mathrm{AB}$ responds in the same way or not. On the one hand, the lack of an inhibitory reaction may be expected to produce a different outcome. On the other hand, it is also conceivable that a stronger $\mathrm{T} 1$ representation simply occupies the global cognitive resource pool to a greater extent, to the detriment of the representation of T2.

\section{Conclusions}

The $A B$ can have two qualitatively different faces, such that blinked items are either completely or only gradually lost for report. Theories of conscious awareness that have taken the supposedly discrete nature of the $\mathrm{AB}$ as indicative of the nature of awareness may thereby have been misguided. Models of temporal attention that have attributed the AB to an inhibitory gating mechanism will need to account for the location-specificity of that effect, and explain how an impoverished, gradual target representation may emerge from the $\mathrm{AB}$. It would seem that a competitive interaction at a post-perceptual level (possibly in working memory) may be the ultimate bottleneck in high-speed target processing. 


\section{Acknowledgements}

AK and EGA were supported by an Open Research Area grant (464.18.114) from the Dutch

Research Council (NWO), the Deutsche Forschungsgemeinschaft (DFG), and the Economic and

Social Research Council (ESRC). JW was supported by an Abel Tasman Talent Grant from the

Graduate School of Medical Sciences of the University of Groningen and Shenzhen University. 


\section{References}

Akyürek, E. G., \& Hommel, B. (2007). Stimulus and response priming in rapid serial visual presentation: Evidence for a dissociation. Perception \& Psychophysics, 69(7), 1152-1161. doi:10.3758/bf03193952

Akyürek, E. G., Eshuis, S. A. H., Nieuwenstein, M. R., Saija, J. D., Başkent, D., \& Hommel, B. (2012). Temporal target integration underlies performance at lag 1 in the attentional blink. Journal of Experimental Psychology: Human Perception and Performance, 38(6), 14481464. doi:10.1037/a0027610

Anllo-Vento, L., \& Hillyard, S. A. (1996). Selective attention to the color and direction of moving stimuli: Electrophysiological correlates of hierarchical feature selection. Perception \& Psychophysics, 58(2), 191-206. doi:10.3758/bf03211875

Asplund, C. L., Fougnie, D., Zughni, S., Martin, J. W., \& Marois, R. (2014). The attentional blink reveals the probabilistic nature of discrete conscious perception. Psychological Science, 25(3), 824-831. doi:10.1177/0956797613513810

Baars, B. J. (1989). A Cognitive Theory of Consciousness. Cambridge, U.K.: Cambridge University Press.

Bays, P. M., Catalao, R. F. G., \& Husain, M. (2009). The precision of visual working memory is set by allocation of a shared resource. Journal of Vision, 9(10), 7-7. doi:10.1167/9.10.7

Bowman, H., Filetti, M., Janssen, D., Su, L., Alsufyani, A., \& Wyble, B. (2013). Subliminal salience search illustrated: EEG identity and deception detection on the fringe of awareness. PLoS ONE, 8(1), e54258. doi:10.1371/journal.pone.0054258

Breitmeyer, B. G., Ehrenstein, A., Pritchard, K., Hiscock, M., \& Crisan, J. (1999). The roles of location specificity and masking mechanisms in the attentional blink. Perception \& Psychophysics, 61(5), 798-809. doi:10.3758/bf03206898 
Broadbent, D. E., \& Broadbent, M. H. P. (1987). From detection to identification: Response to multiple targets in rapid serial visual presentation. Perception \& Psychophysics, 42(2), 105-113. doi:10.3758/bf03210498

Bundesen, C., Habekost, T., \& Kyllingsbæk, S. (2005). A neural theory of visual attention: Bridging cognition and neurophysiology. Psychological Review, 112(2), 291-328. doi:10.1037/0033-295x.112.2.291

Chun, M. M., \& Potter, M. C. (1995). A two-stage model for multiple target detection in rapid serial visual presentation. Journal of Experimental Psychology: Human Perception and Performance, 21, 109-127. doi: 10.1037/0096-1523.21.1.109

Dehaene, S., Sergent, C., \& Changeux, J.-P. (2003). A neuronal network model linking subjective reports and objective physiological data during conscious perception. Proceedings of the National Academy of Sciences, 100(14), 8520-8525. doi:10.1073/pnas.1332574100

Dell'Acqua, R., Pascali, A., Jolicoeur, P., \& Sessa, P. (2003). Four-dot masking produces the attentional blink. Vision Research, 43(18), 1907-1913. doi:10.1016/s00426989(03)00308-0

Dell' Acqua, R., Sessa, P., Jolicoeur, P., \& Robitaille, N. (2006). Spatial attention freezes during the attention blink. Psychophysiology, 43, 394-400. doi:10.1111/j.14698986.2006.00411.x

Denison, R. N., Heeger, D. J., \& Carrasco, M. (2017). Attention flexibly trades off across points in time. Psychonomic Bulletin \& Review, 24(4), 1142-1151. doi:10.3758/s13423-016$1216-1$

Donchin, E., \& Coles, M. G. H. (1988). Is the P300 component a manifestation of context updating? Behavioral and Brain Sciences, 11(03), 357. doi:10.1017/s0140525x00058027 
Duncan, J., Martens, S., \& Ward, R. (1997). Restricted attentional capacity within but not between sensory modalities. Nature, 387(6635), 808-810. doi:10.1038/42947

Duncan, J., Ward, R., \& Shapiro, K. (1994). Direct measurement of attentional dwell time in human vision. Nature, 369(6478), 313-315. doi:10.1038/369313a0

Dux, P. E., \& Marois, R. (2009). The attentional blink: A review of data and theory. Attention, Perception \& Psychophysics, 71(8), 1683-1700. doi:10.3758/app.71.8.1683

Endsley, M.R. (1995). Toward a theory of situation awareness in dynamic systems. Human Factors, 37, 32-64. doi: 10.1518/001872095779049543

Faul, F., Erdfelder, E., Lang, A.-G., \& Buchner, A. (2007). G*Power 3: A flexible statistical power analysis program for the social, behavioral, and biomedical sciences. Behavior Research Methods, 39, 175-191.

Giesbrecht, B., Sy, J. L., \& Elliott, J. C. (2007). Electrophysiological evidence for both perceptual and postperceptual selection during the attentional blink. Journal of Cognitive Neuroscience, 19(12), 2005-2018. doi:10.1162/jocn.2007.19.12.2005

Hannula, D. E., Simons, D. J., \& Cohen, N. J. (2005). Imaging implicit perception: promise and pitfalls. Nature Reviews Neuroscience, 6(3), 247-255. doi:10.1038/nrn1630

Hillyard, S. A., \& Münte, T. F. (1984). Selective attention to color and location: An analysis with event-related brain potentials. Perception \& Psychophysics, 36(2), 185-198. doi:10.3758/bf03202679

Hommel, B., \& Akyürek, E. G. (2005). Lag-1 sparing in the attentional blink: Benefits and costs of integrating two events into a single episode. The Quarterly Journal of Experimental Psychology Section A, 58(8), 1415-1433. doi:10.1080/02724980443000647 
Hubel, D. H., \& Wiesel, T. N. (1974). Sequence regularity and geometry of orientation columns in the monkey striate cortex. The Journal of Comparative Neurology, 158(3), 267-293. doi:10.1002/cne.901580304

Itti, L., \& Koch, C. (2000). A saliency-based search mechanism for overt and covert shifts of visual attention. Vision Research, 40(10-12), 1489-1506. doi:10.1016/s00426989(99)00163-7

JASP Team, (2018). JASP (Version 0.9).

Jolicœur, P., \& Dell'Acqua, R. (1998). The demonstration of short-term consolidation. Cognitive Psychology, 36(2), 138-202. doi:10.1006/cogp.1998.0684

Kanwisher, N. G. (1987). Repetition blindness: Type recognition without token individuation. Cognition, 27(2), 117-143. doi:10.1016/0010-0277(87)90016-3

Kok, A. (2001). On the utility of P3 amplitude as a measure of processing capacity. Psychophysiology, 38(3), 557-577. doi:10.1017/s0048577201990559

Kranczioch, C., Debener, S., \& Engel, A. K. (2003). Event-related potential correlates of the attentional blink phenomenon. Cognitive Brain Research, 17(1), 177-187. doi:10.1016/s0926-6410(03)00092-2

Krause, F., \& Lindemann, O. (2013). Expyriment: A Python library for cognitive and neuroscientific experiments. Behavior Research Methods, 46(2), 416-428. doi:10.3758/s13428-013-0390-6

Kristjánsson, Á., \& Nakayama, K. (2002). The attentional blink in space and time. Vision Research, 42(17), 2039-2050. doi:10.1016/s0042-6989(02)00129-3

Kutas, M., \& Federmeier, K. D. (2011). Thirty years and counting: Finding meaning in the N400 component of the event-related brain potential (ERP). Annual Review of Psychology, 62(1), 621-647. doi:10.1146/annurev.psych.093008.131123 
Kutas, M., \& Hillyard, S. (1980). Reading senseless sentences: Brain potentials reflect semantic incongruity. Science, 207(4427), 203-205. doi:10.1126/science.7350657

Lakens, D. (2013). Calculating and reporting effect sizes to facilitate cumulative science: A practical primer for t-tests and ANOVAs. Frontiers in Psychology, 4. doi:10.3389/fpsyg.2013.00863

Luck, S. J., Hillyard, S. A., Mouloua, M., Woldorff, M. G., Clark, V. P., \& Hawkins, H. L. (1994). Effects of spatial cuing on luminance detectability: Psychophysical and electrophysiological evidence for early selection. Journal of Experimental Psychology: Human Perception and Performance, 20(4), 887-904. doi:10.1037/0096-1523.20.4.887

Luck, S. J., Vogel, E. K., \& Shapiro, K. L. (1996). Word meanings can be accessed but not reported during the attentional blink. Nature, 383(6601), 616-618. doi:10.1038/383616a0

Lunau, R., \& Olivers, C. N. L. (2010). The attentional blink and lag 1 sparing are nonspatial. Attention, Perception, \& Psychophysics, 72(2), 317-325. doi:10.3758/app.72.2.317

Martens, S., \& Wyble, B. (2010). The attentional blink: Past, present, and future of a blind spot in perceptual awareness. Neuroscience \& Biobehavioral Reviews, 34(6), 947-957. doi:10.1016/j.neubiorev.2009.12.005

Mathôt, S., Schreij, D., \& Theeuwes, J. (2012). OpenSesame: An open-source, graphical experiment builder for the social sciences. Behavior Research Methods, 44(2), 314-324. doi:10.3758/s13428-011-0168-7

Näätänen, R., \& Winkler, I. (1999). The concept of auditory stimulus representation in cognitive neuroscience. Psychological Bulletin, 125(6), 826-859. doi:10.1037/0033-2909.125.6.826

Olivers, C. N. L., \& Meeter, M. (2008). A boost and bounce theory of temporal attention. Psychological Review, 115(4), 836-863. doi:10.1037/a0013395 
Olivers, C. N. L., \& Nieuwenhuis, S. (2006). The beneficial effects of additional task load, positive affect, and instruction on the attentional blink. Journal of Experimental Psychology: Human Perception and Performance, 32(2), 364-379. doi:10.1037/00961523.32 .2 .364

Overgaard, M., Rote, J., Mouridsen, K., \& Ramsøy, T. Z. (2006). Is conscious perception gradual or dichotomous? A comparison of report methodologies during a visual task. Consciousness and Cognition, 15(4), 700-708. doi:10.1016/j.concog.2006.04.002

Petersen, A., Kyllingsbæk, S., \& Bundesen, C. (2012). Measuring and modeling attentional dwell time. Psychonomic Bulletin \& Review, 19, 1029-1046. doi:10.3758/s13423-012-0286-y

Polich, J. (2007). Updating P300: An integrative theory of P3a and P3b. Clinical Neurophysiology, 118(10), 2128-2148. doi:10.1016/j.clinph.2007.04.019

Posner, M. I. (1994). Attention: The mechanisms of consciousness. Proceedings of the National Academy of Sciences, 91(16), 7398-7403. doi:10.1073/pnas.91.16.7398

Ramsøy, T. Z., \& Overgaard, M. (2004). Introspection and subliminal perception. Phenomenology and the Cognitive Sciences, 3(1), 1-23. doi:10.1023/b:phen.0000041900.30172.e8

Raymond, J. E., Shapiro, K. L., \& Arnell, K. M. (1992). Temporary suppression of visual processing in an RSVP task: An attentional blink? Journal of Experimental Psychology: Human Perception and Performance, 18(3), 849-860. doi:10.1037/0096-1523.18.3.849

Ricker, T. J., \& Hardman, K. O. (2017). The nature of short-term consolidation in visual working memory. Journal of Experimental Psychology: General, 146(11), 1551-1573. doi:10.1037/xge0000346 
Sandberg, K., Timmermans, B., Overgaard, M., \& Cleeremans, A. (2010). Measuring consciousness: Is one measure better than the other? Consciousness and Cognition, 19(4), 1069-1078. doi:10.1016/j.concog.2009.12.013

Sergent, C., Baillet, S., \& Dehaene, S. (2005). Timing of the brain events underlying access to consciousness during the attentional blink. Nature Neuroscience, 8(10), 1391-1400. doi:10.1038/nn1549

Sergent, C., \& Dehaene, S. (2004). Is consciousness a gradual phenomenon? Evidence for an allor-none bifurcation during the attentional blink. Psychological Science, 15(11), 720-728. doi:10.1111/j.0956-7976.2004.00748.x

Shapiro, K. L., Raymond, J. E., \& Arnell, K. M. (1994). Attention to visual pattern information produces the attentional blink in rapid serial visual presentation. Journal of Experimental Psychology: Human Perception and Performance, 20(2), 357-371. doi:10.1037/00961523.20.2.357

Shapiro, K. L., Schmitz, F., Martens, S., Hommel, B., \& Schnitzler, A. (2006). Resource sharing in the attentional blink. Neuroreport, 17(2), 163-166. doi: 10.1097/01.wnr.0000195670.37892.1a

Suchow, J. W., Brady, T. F., Fougnie, D., \& Alvarez, G. A. (2013). Modeling visual working memory with the MemToolbox. Journal of Vision, 13(10):9, 1-8. doi:10.1167/13.10.9

Taatgen, N. A., Juvina, I., Schipper, M., Borst, J. P., \& Martens, S. (2009). Too much control can hurt: A threaded cognition model of the attentional blink. Cognitive Psychology, 59(1), 129. doi:10.1016/j.cogpsych.2008.12.002

Treisman, A. M., \& Gelade, G. (1980). A feature-integration theory of attention. Cognitive Psychology, 12(1), 97-136. doi:10.1016/0010-0285(80)90005-5 
Verleger, R., Jaśkowski, P., \& Wascher, E. (2005). Evidence for an integrative role of P3b in linking reaction to perception. Journal of Psychophysiology, 19(3), 165-181. doi:10.1027/0269-8803.19.3.165

Visser, T. A. W. (2007). T1 difficulty and the attentional blink: Expectancy versus backward masking. Quarterly Journal of Experimental Psychology, 60(7), 936-951. doi:10.1080/17470210600847727

Visser, T. A. W., Bischof, W. F., \& Di Lollo, V. (1999). Attentional switching in spatial and nonspatial domains: Evidence from the attentional blink. Psychological Bulletin, 125(4), 458-469. doi:10.1037/0033-2909.125.4.458

Visser, T. A. W., Zuvic, S. M., Bischof, W. F., \& Di Lollo, V. (1999). The attentional blink with targets in different spatial locations. Psychonomic Bulletin \& Review, 6(3), 432-436. doi:10.3758/bf03210831

Vogel, E. K., Luck, S. J., \& Shapiro, K. L. (1998). Electrophysiological evidence for a postperceptual locus of suppression during the attentional blink. Journal of Experimental Psychology: Human Perception and Performance, 24(6), 1656-1674. doi:10.1037/00961523.24.6.1656

Vogel, E. K., Woodman, G. F., \& Luck, S. J. (2006). The time course of consolidation in visual working memory. Journal of Experimental Psychology: Human Perception and Performance, 32(6), 1436-1451. doi:10.1037/0096-1523.32.6.1436

Westfall, P. H., Johnson, W. O., \& Utts, P. M. (1997). A Bayesian perspective on the Bonferroni adjustment. Biometrika, 84(2), 419-427. doi:10.1093/biomet/84.2.419

Wierda, S. M., van Rijn, H., Taatgen, N. A., \& Martens, S. (2012). Pupil dilation deconvolution reveals the dynamics of attention at high temporal resolution. Proceedings of the National Academy of Sciences, 109(22), 8456-8460. doi: 10.1073/pnas.1201858109 
Wolfe, J. M. (1994). Guided Search 2.0: A revised model of visual search. Psychonomic Bulletin \& Review, 1(2), 202-238. doi:10.3758/bf03200774

Woodman, G. F., \& Vogel, E. K. (2008). Selective storage and maintenance of an object's features in visual working memory. Psychonomic Bulletin \& Review, 15(1), 223-229. doi:10.3758/PBR.15.1.223

Wyble, B., Bowman, H., \& Nieuwenstein, M. (2009). The attentional blink provides episodic distinctiveness: Sparing at a cost. Journal of Experimental Psychology: Human Perception and Performance, 35(3), 787-807. https://doi.org/10.1037/a0013902

Wyble, B., \& Swan, G. (2015). Mapping the spatiotemporal dynamics of interference between two visual targets. Attention, Perception, \& Psychophysics, 77(7), 2331-2343. doi:10.3758/s13414-015-0938-X

Zhang, W., \& Luck, S. J. (2008). Discrete fixed-resolution representations in visual working memory. Nature, 453(7192), 233-235. doi:10.1038/nature06860 


\section{Figure Captions}

Figure 1. The experimental tasks used in Experiment 1 and 2. a Trial schematic of Experiment 1. T1 means Target 1 and T2 means Target 2. T1Resp indicates T1 response prompt and T2Resp indicates $T 2$ response prompt. $\boldsymbol{b}$ Trial schematic of Experiment 2. Stimulus timing was identical to Experiment 1. c Stimulus size. Degrees $\left(^{\circ}\right)$ are given in visual angle. $\boldsymbol{d}$ Possible T2 orientation relative to $T 1$ orientation, shown for a $90^{\circ}$ T1. e Possible T2 color from the wheel relative to $T 1$ color shown at $90^{\circ}$.

Figure 2. Results of Experiment 1. a Probability density plot of the model and data. Lines indicate model fit, dots represent individual data, symbols reflects averages, and error bars represent $95 \%$ confidence intervals. $\boldsymbol{b}$ T2|T1 accuracy for short and long SOA conditions. SOA is plotted on the $X$-axis, and the $Y$-axis shows T2|T1 accuracy. Dots represent individual data, symbols reflect averages, and error bars represent 95\% confidence intervals. Whisker plots show median and quartile values. * indicates anecdotal evidence against the null hypothesis, ** indicates substantial evidence against the null hypothesis, *** indicates strong evidence, and **** indicates decisive evidence. $\boldsymbol{c}$ T2|T1 response probability based on model predictions. $\boldsymbol{d}$ T2|T1 precision based on model predictions. Higher scores mean better precision.

Figure 3. Results of Experiment 2. a Probability density plot of the model and data. $\boldsymbol{b}$ $T 2 \mid T 1$ accuracy, c $T 2 \mid T 1$ response probability, $\boldsymbol{d} T 2 \mid T 1$ precision for short and long SOA conditions Figure conventions follow Figure 2.

Figure 4. The experimental tasks used in Experiment 3, 4, and 5. The actual size of the stimuli was identical to Experiment 1 and 2, as was the distance between the center and target/distractor locations. T1Resp means $T 1$ response prompt and T2Resp means $T 2$ response prompt. a Trial schematic of Experiment 3. Dashed lines indicate a variable number of distractors. $\boldsymbol{b}$ Trial schematic of Experiment 4. A different target location trial is shown. Stimulus 
timing was identical to Experiment 3. c Trial schematic of Experiment 5. A different location trial is shown.

Figure 5. Results of Experiment 3. a Probability density plot of the model and data. $\boldsymbol{b}$ $T 2 \mid T 1$ accuracy. $\boldsymbol{c} T 2 \mid T 1$ response probability. $d T 2 \mid T 1$ precision for short and long SOA conditions. Figure conventions follow Figure 2.

Figure 6. Results of Experiment 4. a Probability density plot of the model and data for the main effect of SOA. $\boldsymbol{b}$ Probability density plot of the model and data for the main effect of Location. c Probability density plot of the model and data for each SOA condition in the same location condition. $\boldsymbol{d}$ Probability density plot of the model and data for each SOA condition in the different location condition. $\boldsymbol{e} T 2 \mid T 1$ response probability of the main effect of Location $\boldsymbol{f} T 2 \mid T 1$ response probability of the main effect of SOA $\mathrm{g} T 2 \mid T 1$ response probability of the interaction effect of SOA and Location. $\boldsymbol{h}$ T2|T1 precision of the main effect of Location $\boldsymbol{i}$ T2|T1 precision of the main effect of SOA $j T 2 \mid T 1$ precision of the interaction effect of SOA and Location. Figure conventions follow Figure 2.

Figure 7. Results of Experiment 5. a Probability density plot of the model and data for the main effect of SOA. $\boldsymbol{b}$ Probability density plot of the model and data for the main effect of Location. c Probability density plot of the model and data for each SOA condition in the same location condition. $\boldsymbol{d}$ Probability density plot of the model and data for each SOA condition in the different location condition. $\boldsymbol{e} T 2 \mid T 1$ response probability of the main effect of Location $\boldsymbol{f} T 2 \mid T 1$ response probability of the main effect of SOA $\mathrm{g} T 2 \mid T 1$ response probability of the interaction effect of SOA and Location. $\boldsymbol{h}$ T2|T1 precision of the main effect of Location $\boldsymbol{i}$ T2|T1 precision of the main effect of SOA $j T 2 \mid T 1$ precision of the interaction effect of SOA and Location. Figure conventions follow Figure 2. 


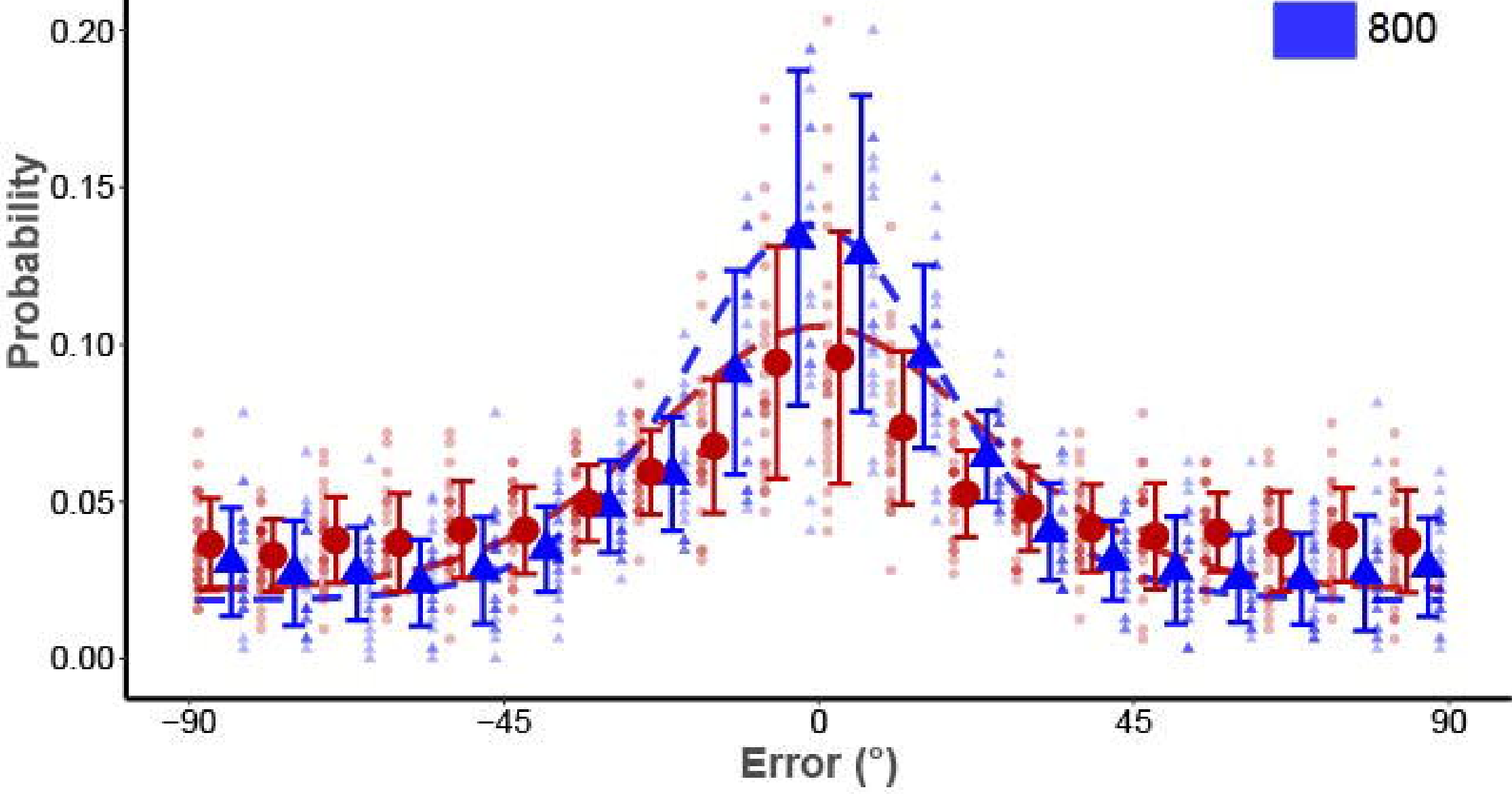

b

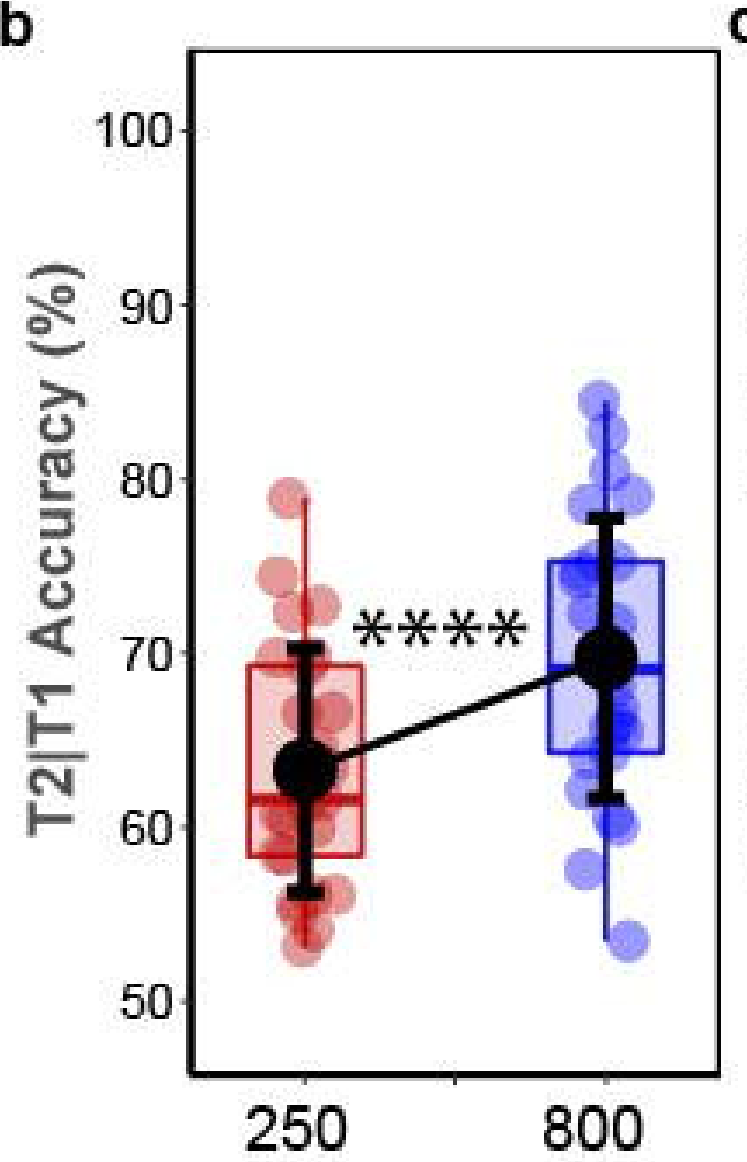

C

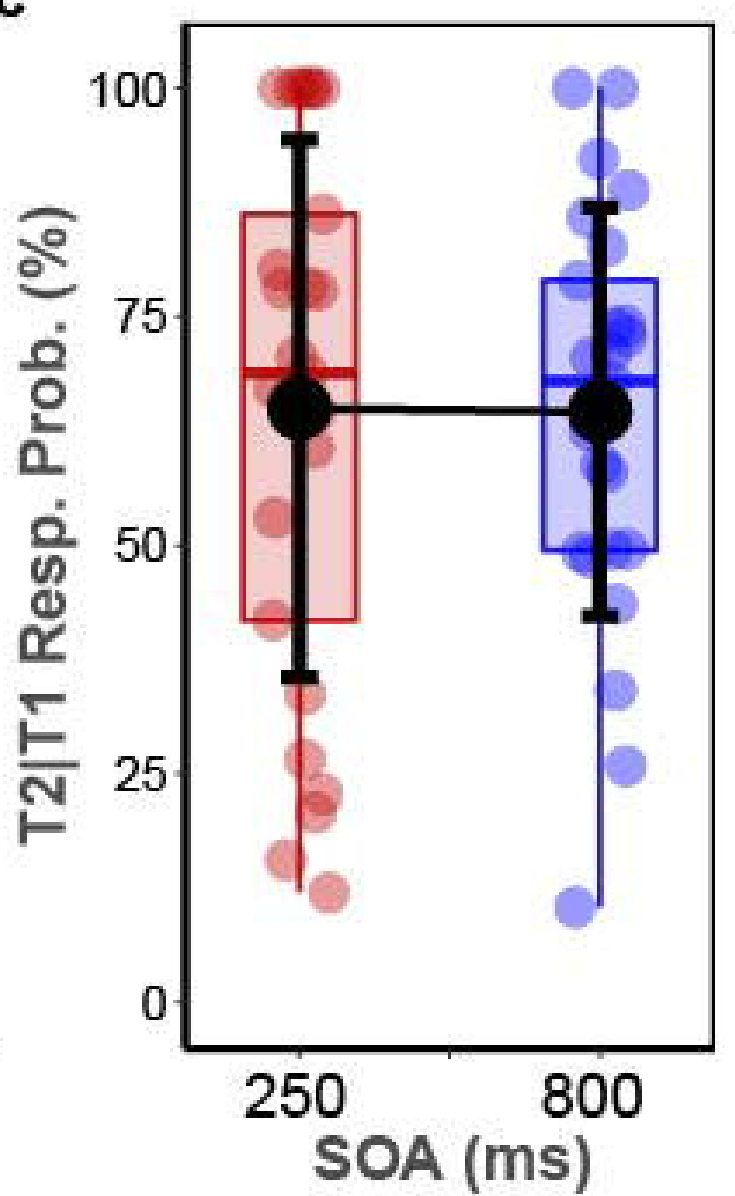

d

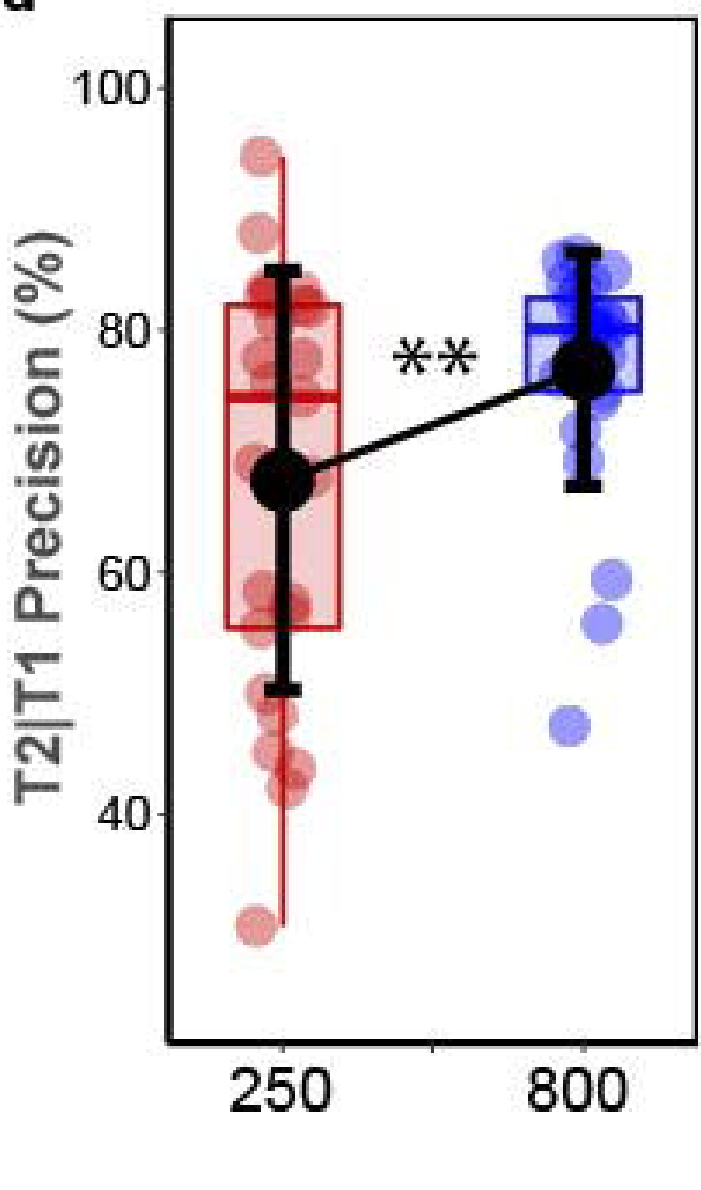



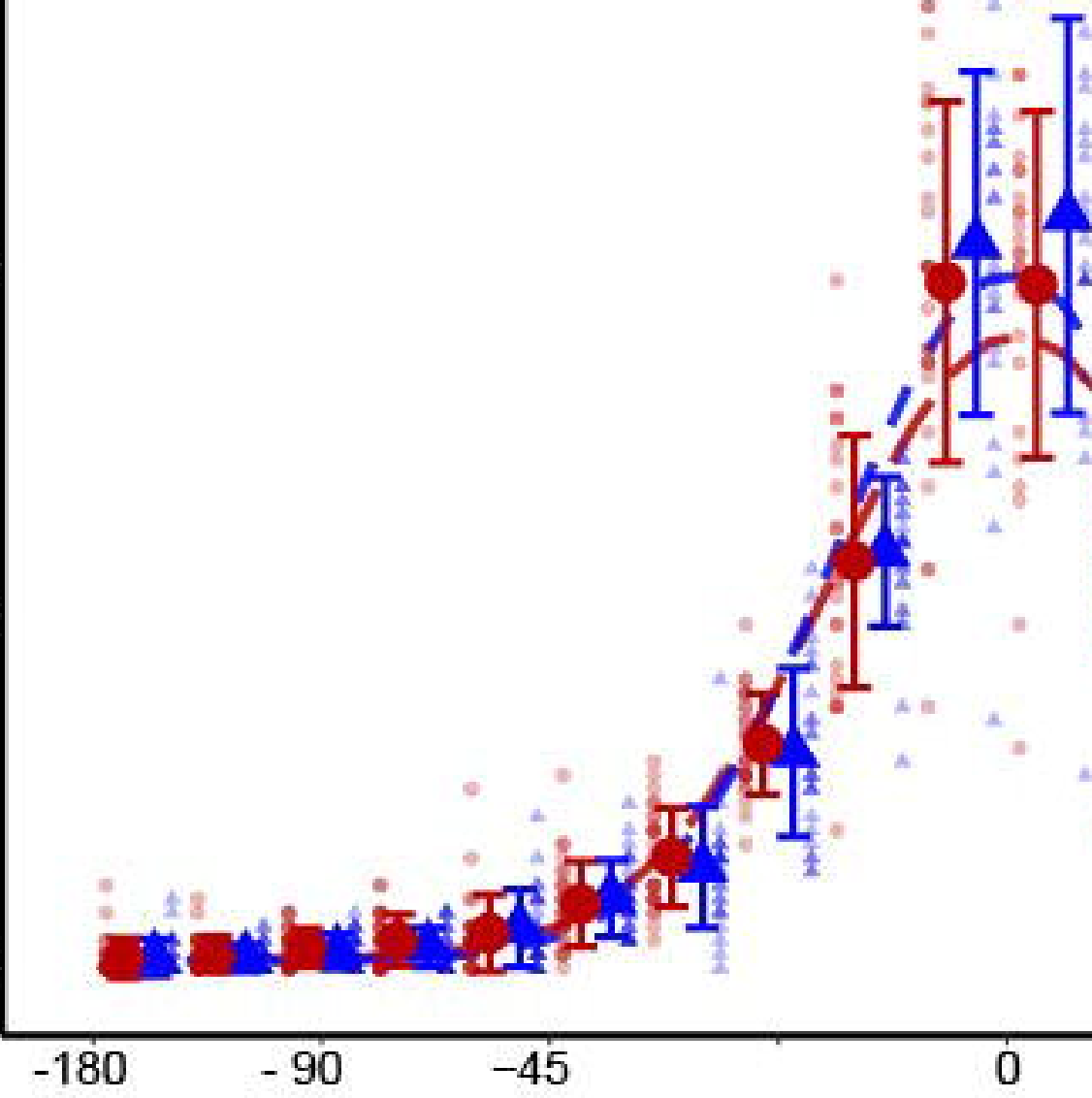

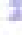
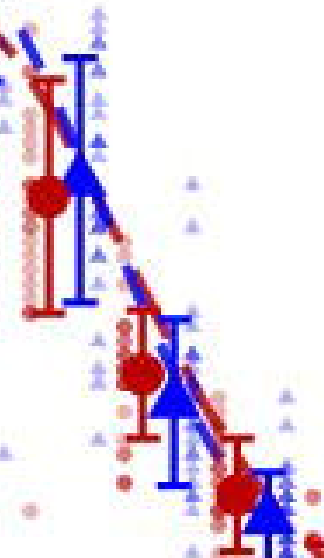

,

-

\section{Error $\left({ }^{\circ}\right)$}

b

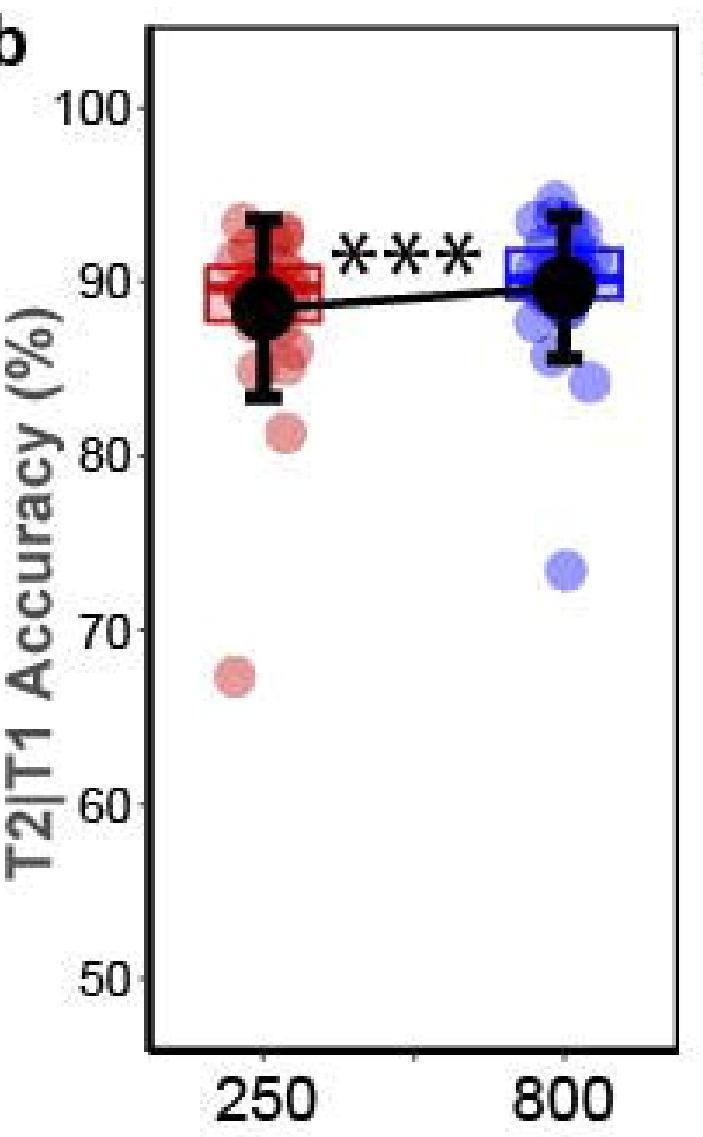

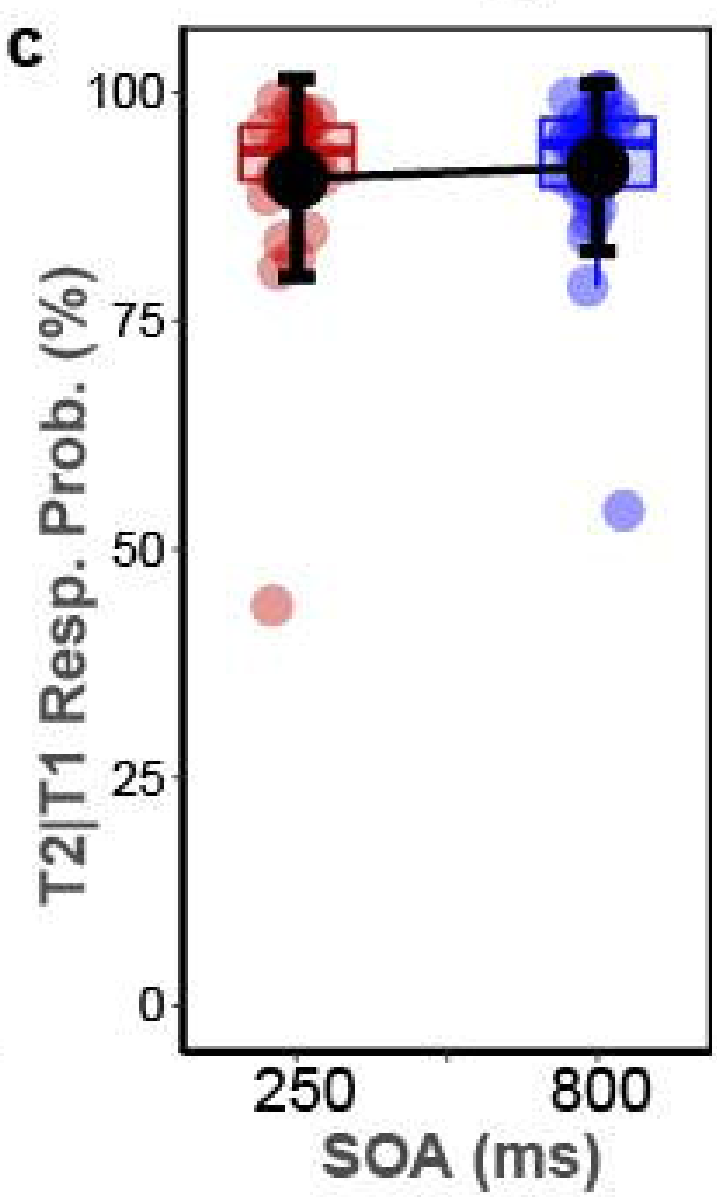

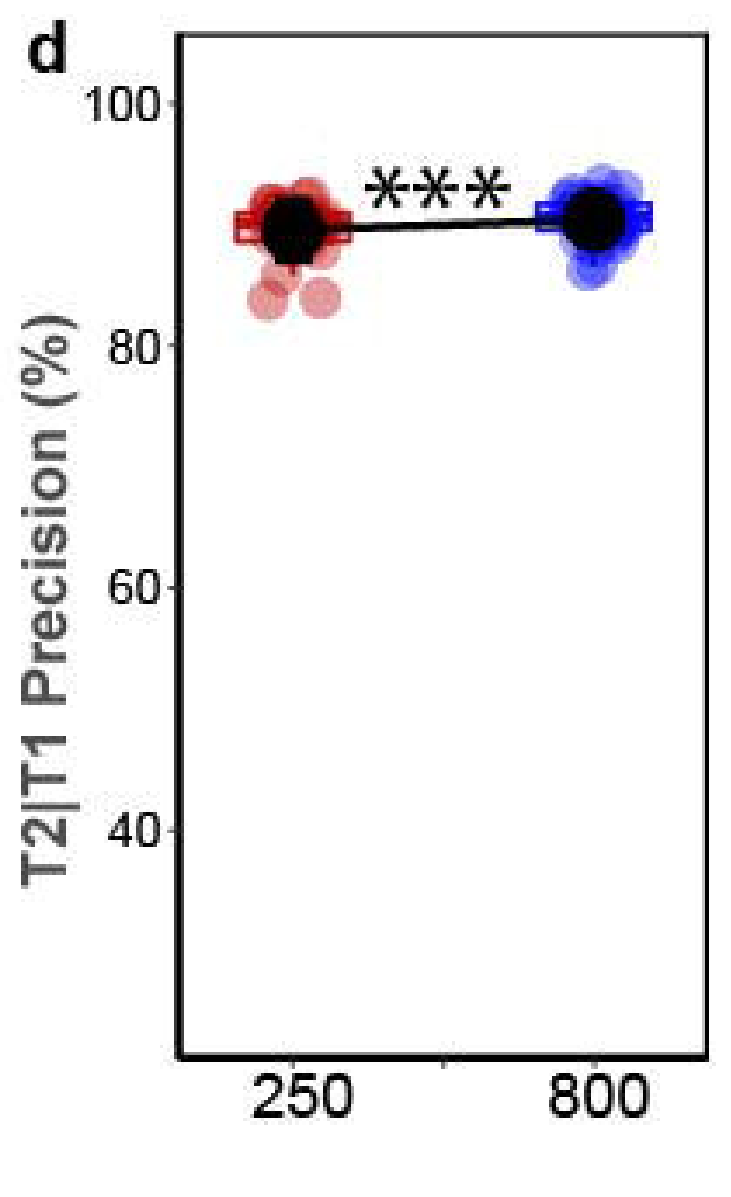




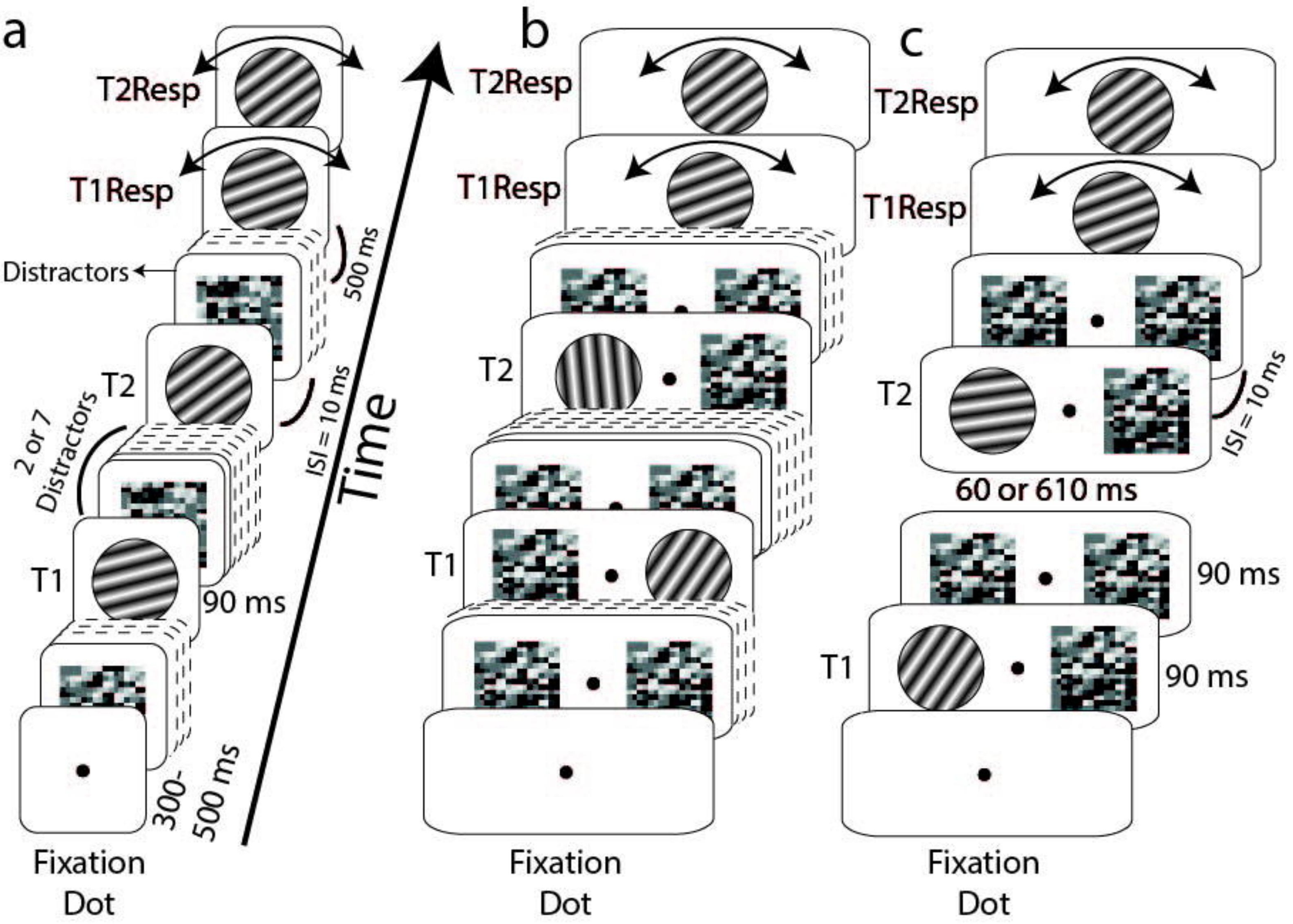




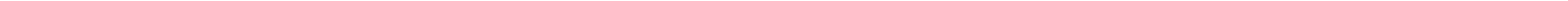




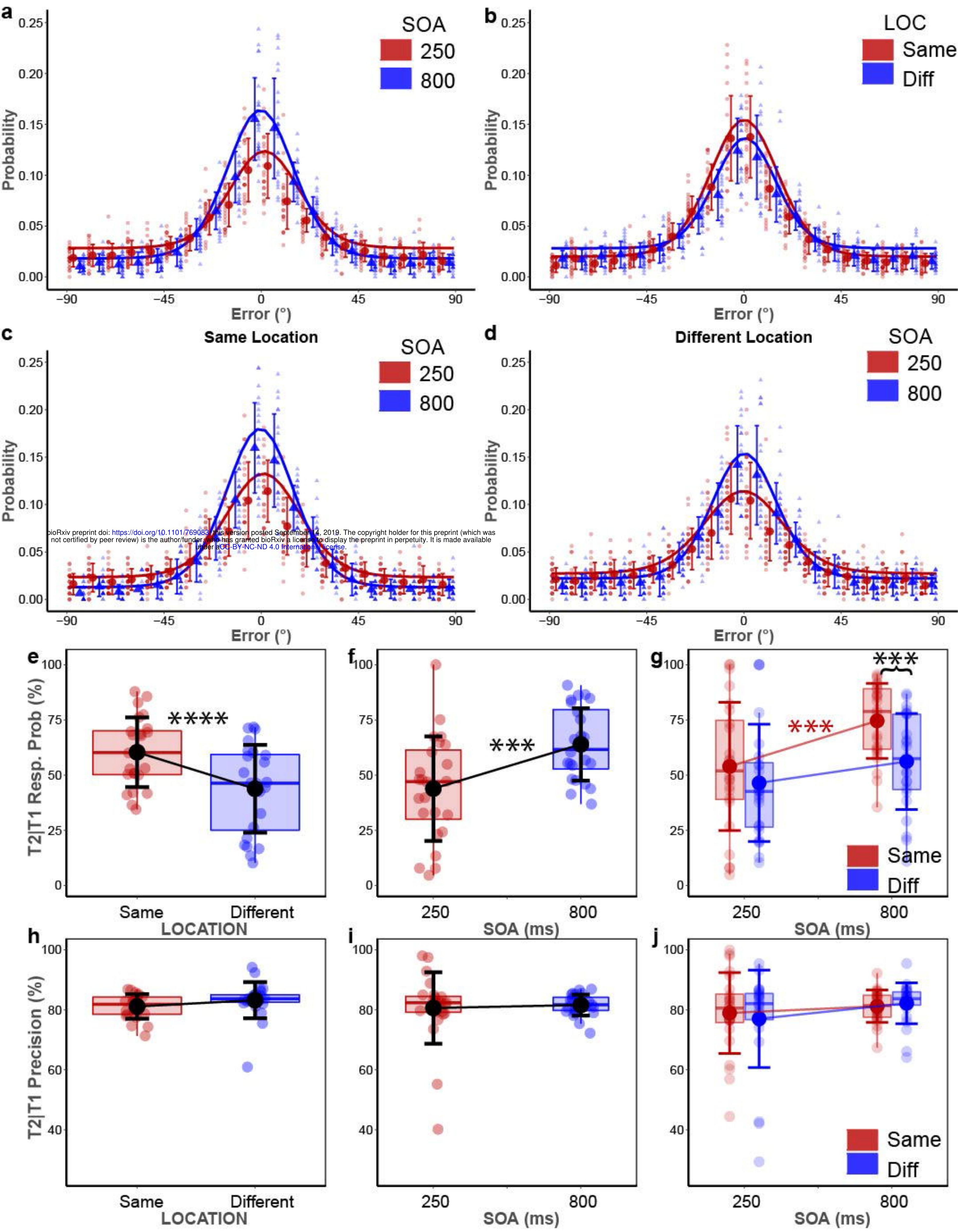

